CrossMark

Cite as

Nano-Micro Lett.

(2019) 11:1

Received: 8 November 2018

Accepted: 16 December 2018

Published online: 8 January 2019

(C) The Author(s) 2019

\section{Recent Progress on Engineering Highly Efficient Porous Semiconductor Photocatalysts Derived from Metal-Organic Frameworks}

\author{
Wenwen Zhan ${ }^{1}$, Liming Sun ${ }^{1}$, Xiguang $\operatorname{Han}^{1}{ }^{凶}$ \\ $\square$ Xiguang Han, xghan@jsnu.edu.cn \\ 1 Jiangsu Key Laboratory of Green Synthetic Chemistry for Functional Materials, Department of Chemistry, \\ School of Chemistry and Chemical Engineering, Jiangsu Normal University, Xuzhou 221116, \\ People's Republic of China
}

\title{
HIGHLIGHTS
}

- In this review, we survey the recent developments in the fabrication of metal-organic framework (MOF)-derived porous semiconductor photocatalysts toward four kinds of energy-/environment-related reactions.

- A comprehensive summary of highly efficient MOF-derived photocatalysts, particularly porous metal oxides and metal sulfides, and their heterostructures are provided.

- Enhanced photocatalytic performance achieved with MOF-derived porous heterostructures as the photocatalyst is discussed in detail.

\begin{abstract}
Porous structures offer highly accessible surfaces and rich pores, which facilitate the exposure of numerous active sites for photocatalytic reactions, leading to excellent performances. Recently, metal-organic frameworks (MOFs) have been considered ideal precursors for well-designed semiconductors with porous structures and/or heterostructures, which have shown enhanced photocatalytic activities. In this review, we summarize the recent development of porous structures, such as metal oxides and metal sulfides, and their heterostructures, derived from MOF-based materials as catalysts for various light-driven energy-/ environment-related reactions, including water splitting, $\mathrm{CO}_{2}$ reduction, organic redox reaction, and pollution degradation. A summary and outlook section is also included.
\end{abstract}

KEYWORDS Metal-organic frameworks; Derivatives; Porous structure; Photocatalysis

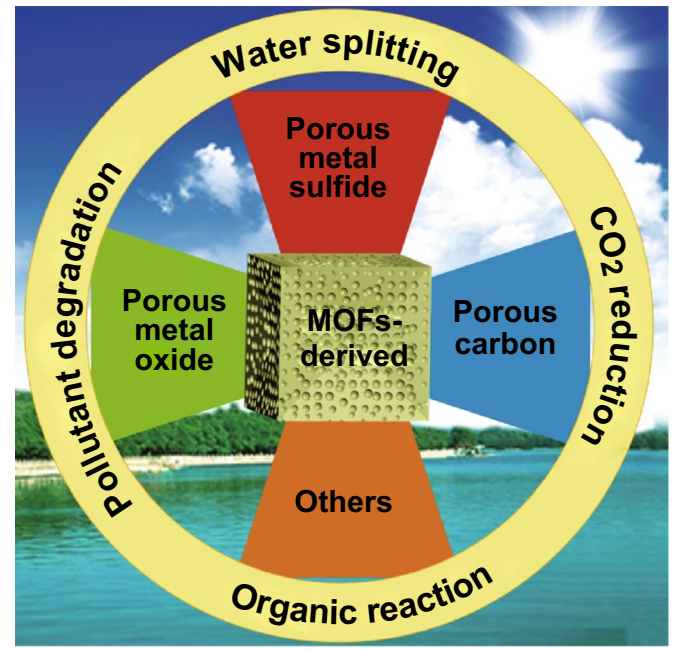




\section{Introduction}

Global energy and environment issues have attracted much attention. Photocatalytic chemical processes, including hydrogen $\left(\mathrm{H}_{2}\right)$ generation from water, carbon dioxide $\left(\mathrm{CO}_{2}\right)$ reduction, pollution degradation, and organic chemical reactions, can convert solar energy to chemical energy, making them very promising in solving the energy and environment issues in a sustainable and environmentally friendly way [1-4]. Since the discovery of $\mathrm{TiO}_{2}$ as a photocatalyst for $\mathrm{H}_{2}$ production from water, a lot of efforts have been devoted to developing highly efficient semiconductor-based photocatalysts [5-13]. To date, metal oxides such as $\mathrm{ZnO}$ [14-16] and $\mathrm{TiO}_{2}$ [17-21], metal sulfides like CdS [22-24], carbon materials, for example, $\mathrm{g}_{-} \mathrm{C}_{3} \mathrm{~N}_{4}[25,26]$, and their heterostructures have shown great performances in photocatalysis. However, defects in low light utilization efficiency, improper band position, fast recombination of charge carriers, and photocorrosion have accelerated the investigation on strategies to close the gaps and design more efficient photocatalysts.

Porous micro-nanostructures can offer highly accessible surfaces and rich pores, which favor the exposure of numerous active sites in reactions, shorten the transfer distance to the pore surface for photoexcited carriers, and provide unrestricted diffusion of substrates and products, leading to their excellent performances in photocatalysis [27-33]. In addition, fabrication of semiconductor-based heterojunctions, including semiconductor-metal heterojunction and semiconductor-semiconductor heterojunction, is another useful strategy for enhancing the photocatalytic activity [10, 34-42]. Proper heterojunctions can tune the band gap, encourage the separation and migration of photogenerated electron-hole pairs, and enhance the efficiency of light utilization. In the last few years, much progress has been made in the design of photocatalysts with porous structures and heterostructures; however, the rational design of photocatalysts is hard because of complicated processes in traditional synthesis. Therefore, efficient and easily preparable photocatalysts with beneficial structural features are desired.

Recently, MOFs, well known as porous coordination polymers consisting of metal nodes and organic ligands, have attracted much attention and shown great potential for various applications, including photocatalysis, due to their fine-tuned structures, high specific surface areas, controlled pore structures, and various components [43-49]. Moreover, via the well-designed modification of MOFbased materials, not only the reactant adsorption and light absorption but also the charge separation and reactant activation can be largely promoted, leading to enhanced photocatalytic performances [50-53]. However, the poor stability and poor electronic conductivity of MOFs hinder their usage in the photocatalytic field. As an alternative, recent studies have found that MOFs can serve as precursors for porous semiconductor materials, including porous metal oxides, carbon materials, and metal sulfides, and their heterostructures, through the facile thermal treatment or sulfidation process [54-60]. Via the controlled derivation of MOFs in certain conditions, the as-synthesized products can maintain some of the initial structural features of parent MOFs or promote electrical conductivity, while maintaining the open diffusion channels and ensuring the monodispersion of metal centers, making them very promising in photocatalysis. More interestingly, porous heterostructures or solid solutions can be rationally derived from MOFbased hybrids or multimetallic MOFs, and the procedure has the following merits: (1) the versatility of MOFs in metal nodes and ligands endows enough choices for fabricating heterostructures or solid solutions, and the band gap of the obtained derivatives can be easily tuned by altering the metal or component ratios; (2) the in situ synthesis with MOFs as the precursor prevents the poor structural stability and weak coupling between the individual components of a heterostructure and solid solution; and (3) the in situ uniform distribution of metal nodes in multimetallic MOF precursors at the molecular level can contribute to an increase in the active sites, which can effectively participate in photocatalytic reactions. Therefore, MOFs can act as ideal precursors for rationally designed photocatalysts with enhanced performances.

In the past few years, a lot of progress has been made on porous photocatalysts, including porous metal oxides, porous metal sulfides, and porous carbon, and their heterostructures, derived from monometallic MOFs, multimetallic MOFs, or MOF-based hybrids for water-splitting reactions, pollutant degradation, $\mathrm{CO}_{2}$ reduction, and organic synthesis. A timeline showing the breakthrough in the fabrication of highly efficient MOF-derived photocatalysts is shown in Fig. 1. With features of a porous structure and/or heterostructure, 


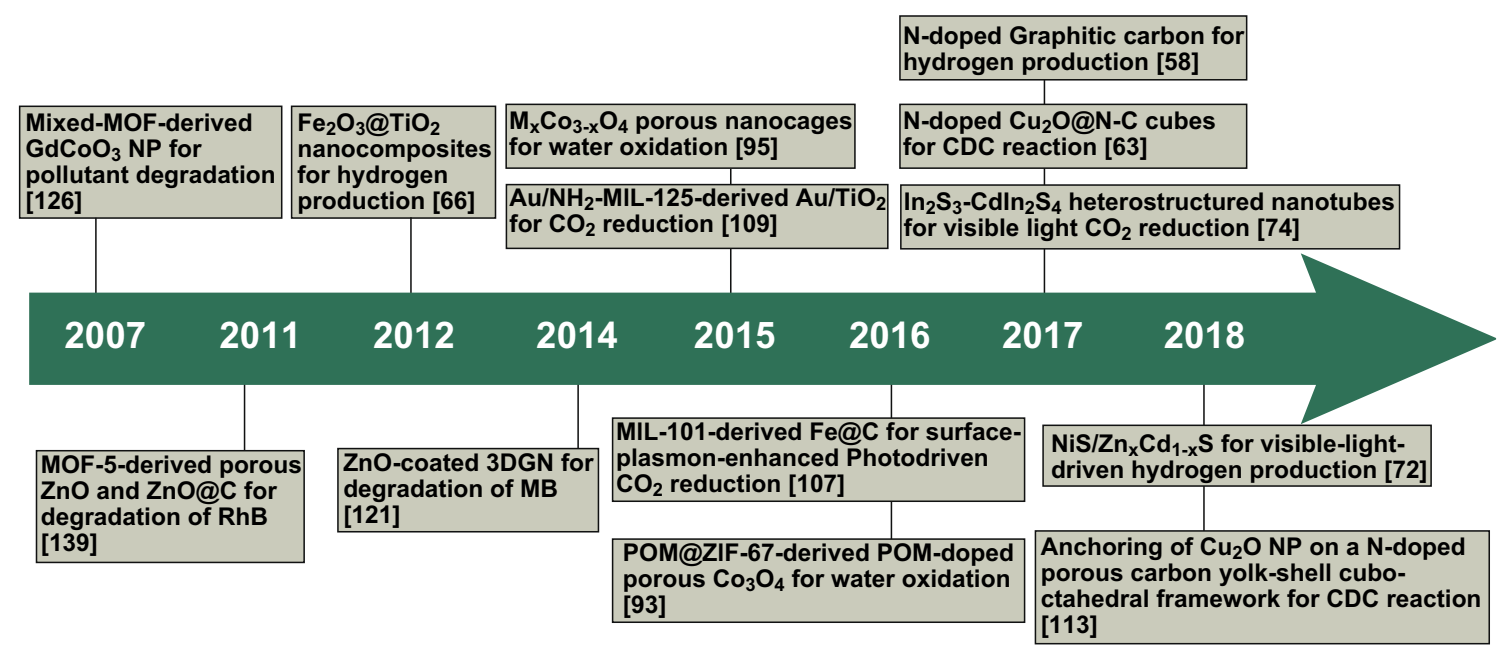

Fig. 1 Timeline of the important breakthroughs in the fabrication of MOF-derived photocatalysts for various reactions

which are beneficial for increasing light utilization efficiency and promoting the separation and migration of photoinduced electron-hole pairs, these MOF-derived photocatalysts have acted well in enhancing photocatalytic performances. However, a specialized discussion on the progress achieved in the photocatalytic application of MOF-derived porous materials is very rare. Herein, we endeavor to give a comprehensive summary of the progress in four parts, i.e., (1) photocatalytic water splitting, including the photocatalytic hydrogen evolution reaction and oxygen evolution reaction; (2) photocatalytic degradation of pollutants, particularly dye pollutants; (3) photocatalytic $\mathrm{CO}_{2}$ reduction to $\mathrm{CO}$ or hydrocarbons; and
(4) photocatalytic organic reactions. A brief summary and outlook are included in the final section.

\section{General Methods}

Firstly, we give a brief summary of the synthetic strategies used to fabricate MOF-derived photocatalysts, including porous metal oxides, porous metal sulfides, and carbon materials. Depending on the different types of MOF-derived photocatalysts, the synthetic strategies can be summarized, as given in Table 1, which includes the corresponding examples.

Table 1 Brief summary of general methods for the fabrication of MOF-derived photocatalysts

\begin{tabular}{|c|c|c|}
\hline MOFs-derived photocatalysts & General methods & Examples \\
\hline $\begin{array}{l}\text { Porous metal oxides; porous metal oxides } \\
\text { doped with } \mathrm{C} \text { or } \mathrm{N}\end{array}$ & $\begin{array}{l}\text { Direct calcination of the corresponding MOFs } \\
\text { under different atmospheres }\end{array}$ & $\begin{array}{l}\text { Porous } \mathrm{ZnO} \text { [61], porous C-doped } \mathrm{ZnO} \text { [62], and } \\
\mathrm{N} \text {-doped } \mathrm{Cu}_{2} \mathrm{O} @ \mathrm{~N}-\mathrm{C} \text { [63] }\end{array}$ \\
\hline Porous metal oxide-based heterostructures & $\begin{array}{l}\text { Direct calcination of heterometallic MOFs } \\
\text { under different atmospheres } \\
\text { Calcination of MOF-based heterostructure }\end{array}$ & $\begin{array}{l}\mathrm{ZnO} / \mathrm{NiO} \text { porous hollow spheres [64] and } \mathrm{ZnO} / \\
\mathrm{Co}_{3} \mathrm{O}_{4}[65] \\
\mathrm{Fe}_{2} \mathrm{O}_{3} @ \mathrm{TiO}_{2}[66], \mathrm{ZnO} / \mathrm{Au} \text { [67], and porous } \\
\mathrm{Co}_{3} \mathrm{O}_{4} / \mathrm{CuO}[68]\end{array}$ \\
\hline Porous metal sulfides & $\begin{array}{l}\text { Direct sulfidation of MOFs } \\
\text { Sulfidation of MOFs' derivative }\end{array}$ & $\begin{array}{l}\text { Yolk-shell CdS [69] } \\
\mathrm{Co}_{4} \mathrm{~S}_{3}[70]\end{array}$ \\
\hline Porous metal sulfides-based heterostructure & $\begin{array}{l}\text { Sulfidation of heterometallic MOFs or their } \\
\text { derivatives } \\
\text { Modification of MOFs' derivatives }\end{array}$ & $\begin{array}{l}\text { Hollow Co-based bimetallic sulfide [71] and NiS/ } \\
\mathrm{Zn}_{x} \mathrm{Cd}_{1-x} \mathrm{~S} \text { [72] } \\
\mathrm{CdS} / \mathrm{ZCO}[73] \text {, and } \mathrm{In}_{2} \mathrm{~S}_{3}-\mathrm{CdIn}_{2} \mathrm{~S}_{4} \text { nanotubes } \\
{[74]}\end{array}$ \\
\hline Porous carbon materials & Direct calcination of MOFs & N-doped graphitic carbon [58] \\
\hline
\end{tabular}




\section{Photocatalytic Water Splitting}

Hydrogen, which can be renewably produced from a variety of (non-fossil) feedstocks, is a globally accepted clean energy carrier. Water splitting, which involves two half-reactions, i.e., hydrogen evolution reaction (HER) and oxygen evolution reaction (OER), has been considered as an attractive route to sustainable $\mathrm{H}_{2}$ generation [75]. Photocatalytic water splitting into $\mathrm{H}_{2}$ and $\mathrm{O}_{2}$ is a typical uphill reaction with a positive Gibbs energy change $\left(\Delta G=+237.13 \mathrm{~kJ} \mathrm{~mol}^{-1}\right)$, which requires a photocatalyst to trigger the reaction and convert solar energy to storable hydrogen energy [76]. Thermodynamically, the conduction band (CB) of the photocatalyst must be located more negative than the $\mathrm{H}^{+} / \mathrm{H}_{2}$ energy level (-0.41 eV vs NHE at pH 7) and the valence band (VB) of the photocatalyst must be located more positive than the $\mathrm{O}_{2} / \mathrm{H}_{2} \mathrm{O}$ energy level $(+0.82 \mathrm{eV}$ vs NHE at $\mathrm{pH}$ 7) [77]. However, the overall water splitting requires higher photon energy than $1.23 \mathrm{eV}$ due to the large overpotential caused by the charge transfer process and interaction between catalysts, reactants, and products. Therefore, the development of an overall water-splitting system remains a great challenge, and photocatalytic water splitting is generally studied separately. To date, many efficient porous photocatalysts derived from MOFs have been developed for HER; however, more progress needs to be made on OER (Table 2).

\subsection{Photocatalytic HER}

In the hydrogen evolution half-reaction system, the other half-reaction is replaced by the oxidation of an appropriate sacrificial reductant, such as methanol, ethanol, triethanolamine, triethylamine, ascorbic acid, lactic acid, and $\mathrm{Na}_{2} \mathrm{~S} /$ $\mathrm{Na}_{2} \mathrm{SO}_{3}$ pairs [77]. Similar to that for other photocatalytic systems, the design principles for the HER photocatalysts involve a suitable band gap, enhanced charge transfer efficiency, and numerous active sites. MOFs serve as ideal precursors for highly efficient HER photocatalysts because of their ability to provide various metal ions (as options), facilitate the doping of $\mathrm{C}$ or $\mathrm{N}$ to MOF-derived semiconductors, and give porous structures with high surface areas.

\subsubsection{MOF-Derived Porous Metal Oxides}

Metal oxide nanostructures, one of the most important semiconductor nanomaterials, have attracted much attention as photocatalysts for water splitting. $\mathrm{TiO}_{2}$ has been considered the most interesting photocatalyst for water splitting, especially for HER, due to its suitable band positions, low cost, low toxicity, high stability, and n-type semiconducting nature $[78,79]$. However, highly efficient $\mathrm{TiO}_{2}$-based photocatalysts need to be developed because factors such as imperfect light absorption range and quick recombination of photoinduced carriers limit the use of pure $\mathrm{TiO}_{2}$. Several studies indicated that fabricating $\mathrm{TiO}_{2}$-based heterojunctions with metals or other semiconducting materials led to extended light absorption to the visible-light range, as well as suppression of the recombination of photoinduced carriers, leading to higher photocatalytic activity [80]. With MOFs as templates or precursors, facile design of $\mathrm{TiO}_{2}$-based heterostructures can be achieved. For example, Lin's group developed a two-step approach to fabricate $\mathrm{Fe}_{2} \mathrm{O}_{3} @ \mathrm{TiO}_{2}$ nanostructures with MIL-101(Fe) as the precursor. First, the MIL-101(Fe)@amorphous $\mathrm{TiO}_{2}$ precursor was obtained by coating MIL-101 nanoparticles with $\mathrm{TiO}_{2}$ (shell) via acid-catalyzed hydrolysis and condensation of titanium(IV) bis(ammonium lactato)dihydroxide (TALH) in water; then, the precursor was calcined in air to obtain $\mathrm{Fe}_{2} \mathrm{O}_{3} @ \mathrm{TiO}_{2}$ nanostructures (Fig. 2) [66]. This heterostructure photocatalyst exhibited interesting properties and enabled visible-light-driven hydrogen production from water, while neither of the individual components had such ability. Xiong's group has also reported a series of hollow $\mathrm{TiO}_{2}$-based photocatalyst derived from the MOF@ $\mathrm{TiO}_{2}$ core-shell precursor for $\mathrm{H}_{2}$ evolution from water [81]. Compared with products obtained via other calcination approaches, $\mathrm{Cu} / \mathrm{TiO}_{2}-\mathrm{AA}$, the product obtained by simultaneous etching and reduction with ascorbic acid (AA), can better preserve the octahedral-shaped shells and crystal phase as well as prevent the formation of carbon residues and cocatalyst aggregation, leading to improved efficiency in photocatalysis. These reports indicate that mixing $\mathrm{TiO}_{2}$ with suitable nanomaterials can offer a solution to enhance its photocatalytic activity because of the synergistic effect.

Accordingly, other MOF-derived $\mathrm{TiO}_{2}$-based heterostructures have been obtained. For instance, the hollow hybrid $\mathrm{Fe}_{2} \mathrm{O}_{3}-\mathrm{TiO}_{2}-\mathrm{PtO}_{x}$ photocatalyst was fabricated with nanosized MIL-88B(Fe)-based heterostructures as a hard 
Table 2 Selected MOF derivatives that serve as photocatalysts for HER and OER

\begin{tabular}{|c|c|c|c|c|c|c|c|c|}
\hline Photocatalyst & MOF precursors & $E_{\mathrm{g}}(\mathrm{eV})$ & $\begin{array}{l}\text { Target } \\
\text { reaction }\end{array}$ & Illumination range & Sacrificial reagent & $\begin{array}{l}\text { Production rate } \\
{\left[\mu \mathrm{mol}(\mathrm{g} \mathrm{h})^{-1}\right]^{\mathrm{a} /}} \\
\text { TOF }\left(\mathrm{s}^{-1}\right)^{\mathrm{b}}\end{array}$ & $\begin{array}{l}\text { Recy- } \\
\text { cled } \\
\text { times }\end{array}$ & $\begin{array}{l}\text { Refer- } \\
\text { ences }\end{array}$ \\
\hline Co- $\mathrm{Zn}_{0.5} \mathrm{Cd}_{0.5} \mathrm{~S}$ & $\mathrm{ZnCo}-\mathrm{ZIF}$ & 2.45 & HER & $\begin{array}{l}\text { Visible light } \\
(>420 \mathrm{~nm})\end{array}$ & $\mathrm{Na}_{2} \mathrm{~S}-\mathrm{Na}_{2} \mathrm{SO}_{3}$ & 17,360 & 6 & [90] \\
\hline $\mathrm{NiS} / \mathrm{Zn}_{0.5} \mathrm{Cd}_{0.5} \mathrm{~S}$ & $\mathrm{Ni} / \mathrm{ZnCd}-\mathrm{MOF}$ & 2.32 & HER & $\begin{array}{l}\text { Visible light } \\
(>420 \mathrm{~nm})\end{array}$ & $\mathrm{Na}_{2} \mathrm{~S}-\mathrm{Na}_{2} \mathrm{SO}_{3}$ & 16,780 & 5 & [72] \\
\hline $\mathrm{Zn}_{0.5} \mathrm{Cd}_{0.5} \mathrm{~S}$ & ZIF-8 & - & HER & $\begin{array}{l}\text { Visible light } \\
(>420 \mathrm{~nm})\end{array}$ & $\mathrm{Na}_{2} \mathrm{~S}-\mathrm{Na}_{2} \mathrm{SO}_{3}$ & 12,130 & 6 & [90] \\
\hline $\mathrm{CdS} / \mathrm{ZCO}$ & $\mathrm{ZnCo}-\mathrm{ZIF}$ & 2.1 & HER & $\begin{array}{l}\text { Visible light } \\
(>420 \mathrm{~nm})\end{array}$ & Lactic acid & 3978.6 & 4 & [73] \\
\hline Yolk-shell CdS & $\mathrm{Cd}-\mathrm{Fe}-\mathrm{PBA}$ & 2.24 & HER & Visible light & $\mathrm{Na}_{2} \mathrm{~S}-\mathrm{Na}_{2} \mathrm{SO}_{3}$ & 3051.4 & 4 & [69] \\
\hline $\begin{array}{l}\text { Hollow } \mathrm{Fe}_{2} \mathrm{O}_{3}- \\
\mathrm{TiO}_{2}-\mathrm{PtO}_{x}\end{array}$ & MIL-88B@ $\mathrm{TiO}_{2}$ & - & HER & $\begin{array}{l}\text { Visible light } \\
\quad(>420 \mathrm{~nm})\end{array}$ & Lactic acid & 1100 & 5 & {$[82]$} \\
\hline HP-CdS & MIL-53(Al) & $\sim 2.4$ & HER & $\begin{array}{l}\text { Visible light } \\
(>380 \mathrm{~nm})\end{array}$ & $\mathrm{Na}_{2} \mathrm{~S}-\mathrm{Na}_{2} \mathrm{SO}_{3}$ & 634 & 4 & [88] \\
\hline $\mathrm{Fe}_{2} \mathrm{O}_{3} @ \mathrm{TiO}_{2}$ & MIL-101@ $\mathrm{TiO}_{2}$ & - & HER & $\begin{array}{l}\text { Visible light } \\
(>420 \mathrm{~nm})\end{array}$ & TEA & $\sim 625$ & 3 & {$[66]$} \\
\hline $\begin{array}{l}\mathrm{FeO}_{x}-\text { carbona- } \\
\text { ceous composites }\end{array}$ & MIL-88B/rGO & - & HER & $\begin{array}{l}\text { Visible light } \\
(>420 \mathrm{~nm})\end{array}$ & TEA & 264.1 & 4 & [85] \\
\hline $\mathrm{ZnO} / \mathrm{Au}$ & $\mathrm{Au} / \mathrm{ZIF}-8$ & 3.17 & HER & $\begin{array}{l}\text { Visible light } \\
(>400 \mathrm{~nm})\end{array}$ & $\mathrm{Na}_{2} \mathrm{~S}-\mathrm{Na}_{2} \mathrm{SO}_{3}$ & 29.8 & 4 & [67] \\
\hline PHIC & In-MIL-68 & - & HER & UV-Vis light & TEOA & $2,700,000$ & 5 & [86] \\
\hline $\begin{array}{l}\text { Hollow } \mathrm{Cu}-\mathrm{TiO}_{2} / \mathrm{C} / \\
\mathrm{Pt}\end{array}$ & $\mathrm{SiO}_{2} @ \mathrm{MOF}-199 / \mathrm{Ti}$ & 2.89 & HER & UV-Vis light & Ethanol & 14,049 & 3 & [91] \\
\hline $\mathrm{Co}_{4} \mathrm{~S}_{3} / \mathrm{CdS}$ & $\mathrm{Co}-\mathrm{MOF}$ & 2.0 & HER & UV-Vis light & Lactic acid & 12,360 & 5 & [70] \\
\hline $\mathrm{Pt}-\mathrm{Zn}_{3} \mathrm{P}_{2}-\mathrm{CoP}$ & $\mathrm{ZnCo}-\mathrm{ZIF}$ & - & HER & UV-Vis light & Methanol & 9150 & 5 & {$[65]$} \\
\hline $\mathrm{Pt}-\mathrm{ZnS}-\mathrm{CoS}$ & $\mathrm{ZnCo}-\mathrm{ZIF}$ & - & HER & UV-Vis light & Methanol & 8210 & 5 & [84] \\
\hline $\mathrm{Pt}-\mathrm{ZnO}-\mathrm{Co}_{3} \mathrm{O}_{4}$ & $\mathrm{ZnCo}-\mathrm{ZIF}$ & - & HER & UV-Vis light & Methanol & 4450 & 5 & {$[83]$} \\
\hline $\mathrm{Co}_{3} \mathrm{O}_{4} / \mathrm{TiO}_{2}$ & Ti/Co-PA & - & HER & UV-Vis light & Methanol & $\sim 7000$ & - & [84] \\
\hline $\mathrm{Pd} / \mathrm{TiO}_{2}$ & $\mathrm{NH}_{2}-\mathrm{MIL}-125$ & $\sim 3.2$ & HER & $\mathrm{UV}-\mathrm{V}$ is light & Methanol & 979.7 & 3 & [83] \\
\hline $\mathrm{Cu} / \mathrm{TiO}_{2}-\mathrm{AA}$ & MOF-199@ $\mathrm{TiO}_{2}$ & - & HER & UV light & Methanol & 62.16 & - & [81] \\
\hline $\begin{array}{l}\text { N-doped graphitic } \\
\text { carbon/Pt }\end{array}$ & ZIF-8 & - & HER & UV-Vis light & TEOA & 18.5 & - & {$[58]$} \\
\hline $\begin{array}{l}\text { N-doped graphitic } \\
\text { carbon }\end{array}$ & ZIF-8 & - & HER & UV-Vis light & TEOA & 5 & - & {$[58]$} \\
\hline $700-\mathrm{CoO}_{x}-\mathrm{C}$ & ZIF-67 & - & OER & $\begin{array}{l}\text { Visible light } \\
(>420 \mathrm{~nm})\end{array}$ & $\begin{array}{c}{\left[\mathrm{Ru}(\mathrm{bpy})_{3}\right]^{2+}-} \\
\mathrm{Na}_{2} \mathrm{~S}_{2} \mathrm{O}_{8}\end{array}$ & 0.039 & 3 & [92] \\
\hline $\begin{array}{c}\mathrm{Co}_{3} \mathrm{O}_{4} / \mathrm{CuO}-3 \\
\mathrm{HPNCs}\end{array}$ & ZIF-67/Cu HD & - & OER & $\begin{array}{l}\text { Visible light } \\
\quad(>420 \mathrm{~nm})\end{array}$ & $\begin{array}{c}{\left[\mathrm{Ru}(\mathrm{bpy})_{3}\right]^{2+}-} \\
\mathrm{Na}_{2} \mathrm{~S}_{2} \mathrm{O}_{8}\end{array}$ & $4.9 \times 10^{-3}$ & 5 & [68] \\
\hline $\begin{array}{l}\text { POM-doped } \\
\text { porous } \mathrm{Co}_{3} \mathrm{O}_{4}\end{array}$ & PW $12 @ Z I F-67$ & - & OER & $\begin{array}{l}\text { Visible light } \\
\quad(>420 \mathrm{~nm})\end{array}$ & $\begin{array}{c}{\left[\mathrm{Ru}(\mathrm{bpy})_{3}\right]^{2+}-} \\
\mathrm{Na}_{2} \mathrm{~S}_{2} \mathrm{O}_{8}\end{array}$ & $1.11 \times 10^{-3}$ & 3 & [93] \\
\hline $\mathrm{Co}_{x} \mathrm{Fe}_{3-x} \mathrm{O}_{4}$ & PBA & - & OER & $\begin{array}{l}\text { Visible light } \\
\quad(>420 \mathrm{~nm})\end{array}$ & $\begin{array}{c}{\left[\mathrm{Ru}(\mathrm{bpy})_{3}\right]^{2+}-} \\
\mathrm{Na}_{2} \mathrm{~S}_{2} \mathrm{O}_{8}\end{array}$ & $5.4 \times 10^{-4}$ & 4 & [94] \\
\hline $\mathrm{Co}_{3} \mathrm{O}_{4}$ nanocages & PBA & - & OER & $\begin{array}{l}\text { Visible light } \\
\quad(>420 \mathrm{~nm})\end{array}$ & $\begin{array}{c}{\left[\mathrm{Ru}(\mathrm{bpy})_{3}\right]^{2+}-} \\
\mathrm{Na}_{2} \mathrm{~S}_{2} \mathrm{O}_{8}\end{array}$ & $3.2 \times 10^{-4}$ & - & [95] \\
\hline $\mathrm{C}, \mathrm{N}$-doped $\mathrm{ZnO}$ & ZIF-8 & 2.98 & OER & $\begin{array}{l}\text { Solar-simulated } \\
\text { light }\end{array}$ & $\mathrm{AgNO}_{3}$ & - & - & [96] \\
\hline
\end{tabular}

${ }^{\text {a }}$ Production rate unit of the listed photocatalytic HER

${ }^{\mathrm{b}}$ Production rate unit of the listed photocatalytic OER 


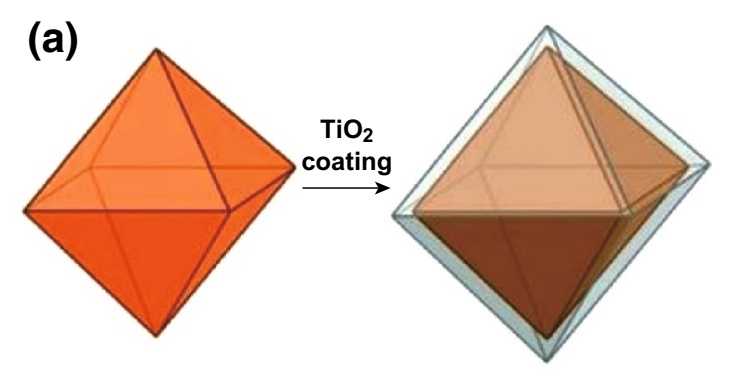

MIL-101

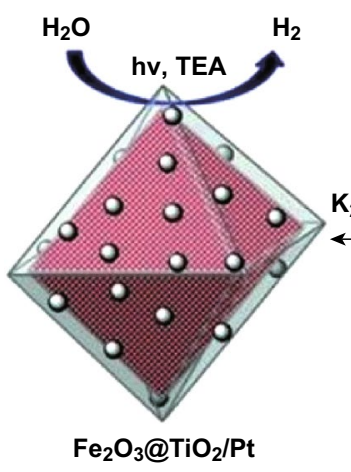

$\mathrm{Fe}_{2} \mathrm{O}_{3} @ \mathrm{TiO}_{2} / \mathrm{Pt}$
MIL-101@TiO

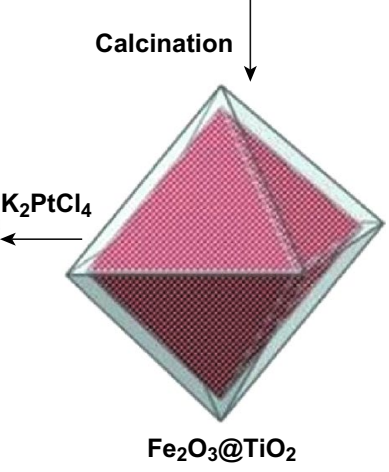

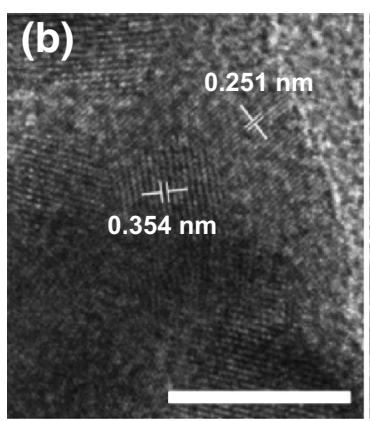

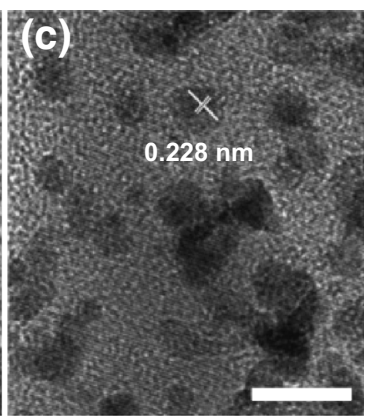

(d)

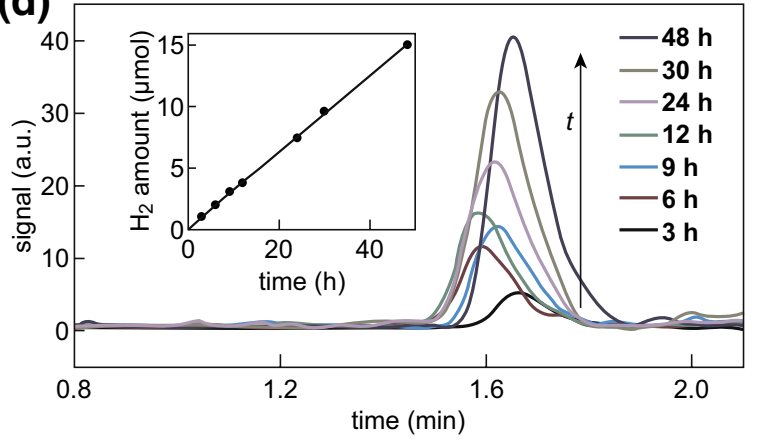

Fig. 2 a Schematic illustration of MOF-templated synthesis of $\mathrm{Fe}_{2} \mathrm{O}_{3} @ \mathrm{TiO}_{2}$ and its use for photocatalytic hydrogen production after deposition of Pt particles; high-resolution TEM images of $\mathrm{Fe}_{2} \mathrm{O}_{3} @ \mathrm{TiO}_{2}$, both $\mathbf{b}$ as-synthesized and $\mathbf{c}$ after Pt particles have been deposited. The scale bars represent $10 \mathrm{~nm} ; \mathbf{d ~ H}_{2}$ produced by $\mathrm{Fe}_{2} \mathrm{O}_{3} @ \mathrm{TiO}_{2}$ at various times over $48 \mathrm{~h}$ under visible-light illumination. The inset shows the amount of $\mathrm{H}_{2}$ produced over this period. Reprinted with permission from Ref. [66]

template [82]. Because of the presence of two cocatalysts on opposite sides, the $\mathrm{Fe}_{2} \mathrm{O}_{3}-\mathrm{TiO}_{2}-\mathrm{PtO}_{x}$ hollow photocatalyst showed high activity toward visible-light-induced $\mathrm{H}_{2}$ generation with a high production rate of $1100 \mu \mathrm{mol}$ $(\mathrm{g} \mathrm{h})^{-1}$, which might be attributed to $\mathrm{Fe}$ doping on $\mathrm{TiO}_{2}$, separation of $\mathrm{PtO}_{x}$ and $\alpha-\mathrm{Fe}_{2} \mathrm{O}_{3}$ nanoparticles as cocatalysts, as well as the short migration distance of electrons and holes to the surface. Besides, combining $\mathrm{TiO}_{2}$ with noble metal materials, $\mathrm{Pd}$ as an example, could be easily prepared with MOF-derived hierarchical $\mathrm{TiO}_{2}$ as support and photoreduction agent at the same time [83]. With a Pd loading amount of $1.5 \%$, the $\mathrm{Pd} / \mathrm{TiO}_{2}$ photocatalyst showed optimized rates of $\mathrm{H}_{2}$ evolution of $\sim 2449$ and $\sim 281.7 \mu \mathrm{mol}$ $(\mathrm{g} \mathrm{h})^{-1}$ under UV-Vis light and simulated solar light, respectively.

As it is an n-type semiconductor, $\mathrm{TiO}_{2}$ can be combined with $\mathrm{p}$-type semiconductors to fabricate $\mathrm{p}-\mathrm{n}$ heterojunctions with enhanced photocatalytic performance due to more effective charge separation; rapid charge transfer to the surface of catalyst; longer lifetime of the charge carriers; and separation of locally incompatible reduction and oxidation reactions in nanospace $[40,41]$. The versatile metal nodes of
MOFs facilitate the facile and rational design of $\mathrm{TiO}_{2}$-based $\mathrm{p}-\mathrm{n}$ heterojunctions. For example, Mondal et al. reported an improved $\mathrm{Co}_{3} \mathrm{O}_{4} / \mathrm{TiO}_{2}$ photocatalytic system with $\mathrm{p}-\mathrm{n}$ heterojunction derived from several newly developed $\mathrm{Co}-\mathrm{MOFs}$ [84]. As mentioned, the obtained $\mathrm{p}-\mathrm{n}$ heterojunction consisted of spinel $\mathrm{Co}_{3} \mathrm{O}_{4}$ and anatase $\mathrm{TiO}_{2}$. With an optimized Co loading of $2 \mathrm{wt} \%$, the $\mathrm{Co}_{3} \mathrm{O}_{4} / \mathrm{TiO}_{2}$ could deliver hydrogen at a high rate of $7000 \mu \mathrm{mol}(\mathrm{g} \mathrm{h})^{-1}$ under UV-Vis light due to the synergistic effect of the formed small heterojunction and cocatalytic role of $\mathrm{Co}_{3} \mathrm{O}_{4}$, which facilitated interfacial charge transfer and electron-hole separation.

Other metal oxide $\left(\operatorname{In}_{2} \mathrm{O}_{3}, \mathrm{ZnO}, \mathrm{Fe}_{2} \mathrm{O}_{3}\right.$, etc.)-based porous photocatalysts with high activities for hydrogen evolution have also been easily prepared with MOFs as templates and/or precursors [67, 85-87]. For instance, an $\mathrm{In}_{2} \mathrm{O}_{3}$-based photocatalyst, namely PHIC, with highly improved activity for hydrogen evolution was fabricated via a facile thermal decomposition of In-MIL-68 template by our group (Fig. 3) [86]. This PHIC catalyst with a hollow hexagonal micro-rod shape was assembled using $\operatorname{In}_{2} \mathrm{O}_{3} @$ carbon core-shell nanoparticles. Due to the synergistic effect of efficient separation of photogenerated electron-hole pairs caused by the carbon 

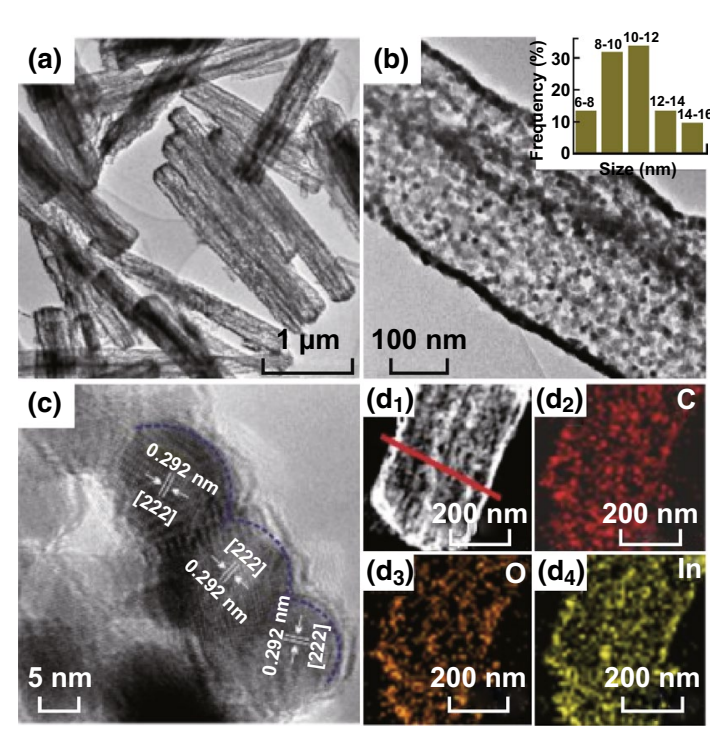
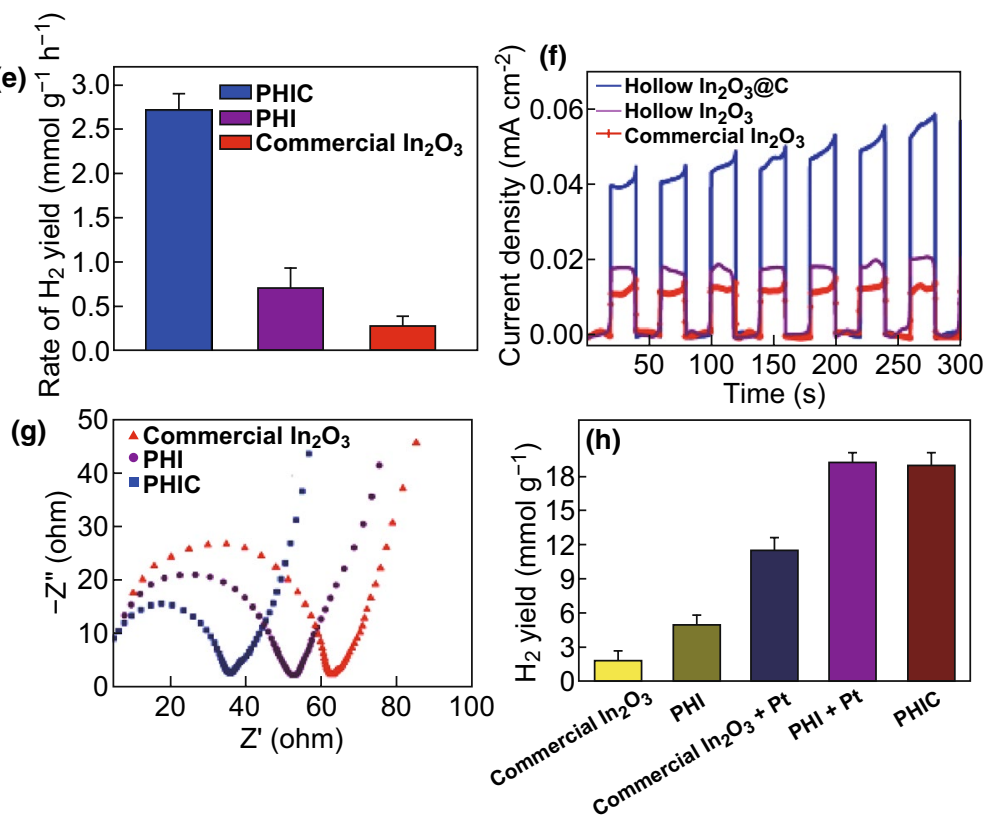

Fig. 3 a-c TEM and HRTEM images of PHIC. d STEM image and EDXS elemental mapping of C, O, and In. e mass-normalized $\mathrm{H}_{2}$ yield rates over PHIC, PHI, and commercial $\mathrm{In}_{2} \mathrm{O}_{3}$ under sunlight illumination. f photocurrent densities of PHIC, PHI, and commercial $\mathrm{In}_{2} \mathrm{O}_{3}$ under non-illuminated (i.e., dark) and illuminated (i.e., light) conditions. g Electrochemical impedance spectroscopy Nyquist plots of PHIC, PHI, and commercial $\mathrm{In}_{2} \mathrm{O}_{3}$. h mass-normalized $\mathrm{H}_{2}$ yield for 7 h over commercial $\mathrm{In}_{2} \mathrm{O}_{3}$, PHI, commercial $\operatorname{In}_{2} \mathrm{O}_{3}$ with Pt, PHI with Pt, and PHIC without Pt under simulated sunlight illumination. Reprinted with permission from Ref. [86]

coating, enhanced optical absorption attributed to hollow characters, and improved accessibility rendered by the porous structure, PHIC could exhibit a photocatalytic activity comparable to that of the $\mathrm{Pt} / \mathrm{In}_{2} \mathrm{O}_{3}$ photocatalyst toward hydrogen evolution with an extremely high production rate of 2,700,000 $\mu \mathrm{mol}(\mathrm{g} \mathrm{h})^{-1}$ under solar-simulated light. In addition, $\mathrm{ZnO}$, a typical semiconductor with absorption in the UV region, has been optimized as a better photocatalyst by compounding it with other materials, such as noble metal nanoparticles (NPs) and other metal oxides. With Zn-MOF/ metal NP hybrids as the precursor, $\mathrm{ZnO}$ /metal NP heteromaterials with porous structures could be easily obtained [67]. Wang group fabricated the $\mathrm{Au} / \mathrm{ZnO} \mathrm{NP}$ photocatalyst with yellow fluorescent GSH-Au nanoclusters (NCs)/ ZIF-8 NPs as the precursor, and this photocatalyst could extend the absorption of $\mathrm{ZnO}$ to the visible-light region. The obtained An/ZnO NP photocatalyst could achieve a hydrogen generation rate of $\sim 29 \mu \mathrm{mol}(\mathrm{g} \mathrm{h})^{-1}$ under visible-light illumination.

\subsubsection{MOF-Derived Porous Metal Sulfides}

Cadmium sulfide (CdS) is another promising photocatalyst for solar-driven hydrogen evolution due to its visible-light response $\left(E_{\mathrm{g}}=2.4 \mathrm{eV}\right)$ and conduction band located at a suitable energy level. However, there are two drawbacks for the CdS photocatalyst, i.e., easy recombination of photogenerated hole-electron pairs and high photocorrosion in aqueous media, which restrict its practical application. In order to enhance the photocatalytic activity of CdS, various strategies have been introduced, including increasing specific surface area and modifying $\mathrm{CdS}$ with cocatalysts or incorporating other materials to form solid solutions, each of which could be handily achieved with the MOF-derivation strategy. Notably, CdS materials with high surface areas as photocatalysts may still suffer from poor stability, but they can demonstrate improved activities by promoting the separation of photoinduced hole-electron pairs. For example, Xiao and Jiang synthesized a hierarchically porous CdS (HP$\mathrm{CdS}$ ) utilizing thermally stable MOFs as hard templates to afford porous $\mathrm{CdO}$, and subsequently, $\mathrm{CdS}$ by a nanocasting method (Fig. 4) [88]. The obtained HP-CdS showed a BET 

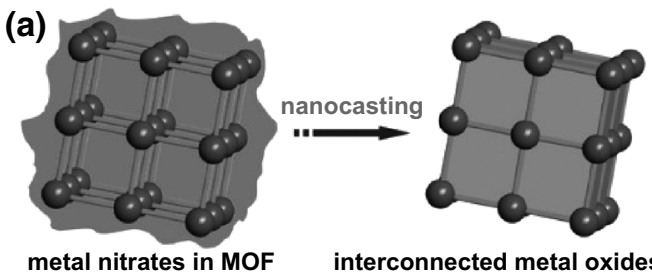

metal nitrates in MOF
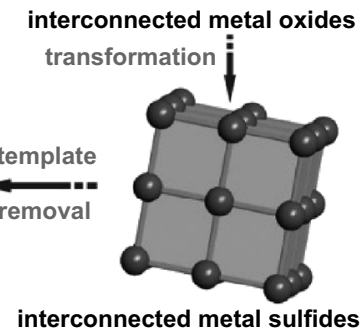

(b)

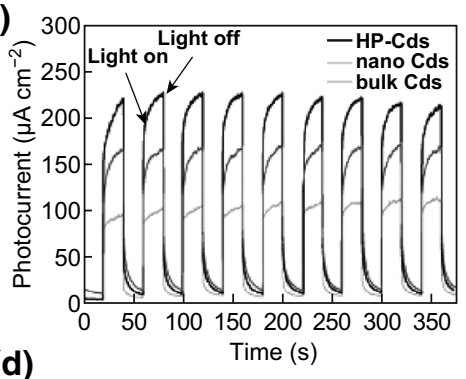

(d)

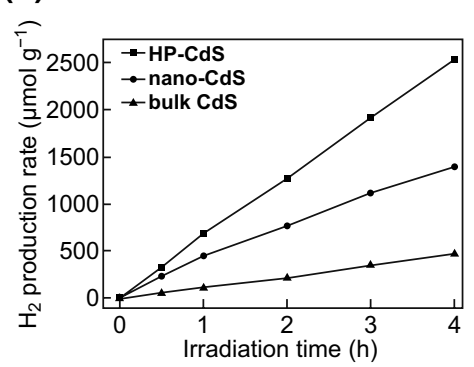

(c)

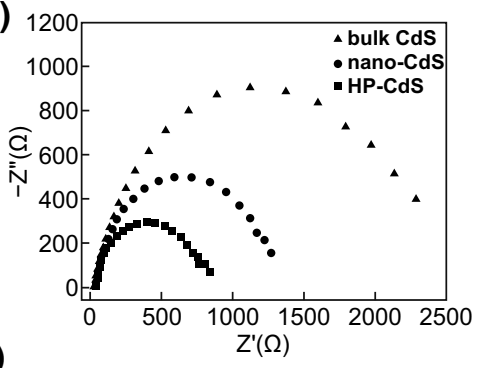

(e)

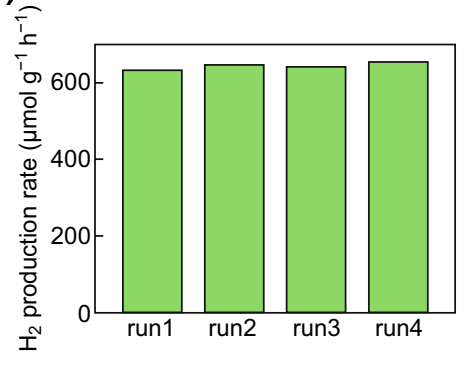

Fig. 4 a Schematic illustration of the synthesis of hierarchically porous metal oxides/sulfides templated by MOFs by a nanocasting process. b Photocurrent response and $\mathbf{c}$ EIS Nyquist plots for bulk CdS, nano-CdS as well as HP-CdS. d Comparison of the photocatalytic hydrogen production rates of bulk CdS, nano-CdS, and HP-CdS. e Catalytic recyclability of HP-CdS in hydrogen production by water splitting. Reprinted with permission from Ref. [88]

surface area of $119 \mathrm{~m}^{2} \mathrm{~g}^{-1}$, which facilitated the effective inhibition of photogenerated electron-hole recombination, leading to a higher photocatalytic activity for HER than nano-CdS and bulk CdS under visible light (>380 nm). In addition, CdS with complex hollow nanostructures, which provides multiple structural advantages for the photocatalytic reaction, such as enhanced light absorption, improved separation efficiency of the photoinduced charge carriers, and increased specific surface area, could be obtained with MOFs as templates or precursors. Wang and Liu et al. have reported the formation of a yolk-shell-structured CdS material by a two-step MOF-based approach, involving facile synthesis of uniform Cd-Fe-PBA micro-cubes and subsequent chemical sulfidation [69]. Due to the structural merits, including a 3D open structure, small size of primary nanoparticles, high specific surface area, and good structural robustness, the yolk-shell-structured CdS material could generate $\mathrm{H}_{2}$ from water under visible-light illumination with an excellent rate of $3051.4 \mu \mathrm{mol}(\mathrm{g} \mathrm{h})^{-1}$.

MOF-based strategies for decorating CdS either with cocatalysts, or by incorporating other materials to form a solid solution, have attracted much attention due to the obvious merits of MOFs, such as variable composition and porosity. For example, $\mathrm{CdS} / \mathrm{Zn}_{x} \mathrm{Co}_{3-x} \mathrm{O}_{4}(\mathrm{CdS} / \mathrm{ZCO})$ hollow composites with high photocatalytic activity for visible-light-induced $\mathrm{H}_{2}$ generation from water have been fabricated by decorating $\mathrm{CdS}$ nanoparticles on $\mathrm{Zn} / \mathrm{Co}-\mathrm{ZIF}$ derivatives $\left(\mathrm{Zn}_{x} \mathrm{Co}_{3-x} \mathrm{O}_{4}\right)$ [73]. With an optimized loading content of $\mathrm{CdS}(30 \%)$ on the ZCO surface, $\mathrm{CdS} / \mathrm{ZCO}$ achieved a high $\mathrm{H}_{2}$ production rate of about $3978.6 \mu \mathrm{mol}$ $(\mathrm{g} \mathrm{h})^{-1}$, which was attributed to the synergistic effect, i.e., the efficient charge separation and transfer between the phase boundary of CdS and ZCO. Similarly, Co-MOF-derived onion slice-type hollow-structured $\mathrm{Co}_{4} \mathrm{~S}_{3}$ was developed and decorated with CdS nanoparticles for photocatalytic hydrogen production by Kim's group [70]. The optimized $\mathrm{Co}_{4} \mathrm{~S}_{3} /$ $\mathrm{CdS}$ material led to an enhanced rate of $\mathrm{H}_{2}$ generation of $12,360 \mu \mathrm{mol}(\mathrm{g} \mathrm{h})^{-1}$ under simulated solar light irradiation. The low density, hollow interior, and shell permeability of the onion-type composite helped in accelerating the charge separation and transfer in photocatalytic reactions. They also prepared MOF-derived $\mathrm{Ni}_{2} \mathrm{P}$ nanoparticles as the cocatalyst of $\mathrm{CdS}$, and the $\mathrm{Ni}_{2} \mathrm{P} / \mathrm{CdS}$ heterostructure exhibited great improvement in performance during photocatalytic HER due to the decreased rate of charge carrier recombination [89]. Moreover, a family of photocatalysts $\left(\mathrm{NiS} / \mathrm{Zn}_{x} \mathrm{Cd}_{1-x} \mathrm{~S}\right)$ for HER has been developed by decorating CdS with $\mathrm{NiS}$ as a cocatalyst and simultaneously incorporating $\mathrm{Zn}$ to form solid solutions [72]. As shown in Fig. 5, Cheng's group utilized $\mathrm{Zn}$ - and Ni-doped Cd-MOFs as the sacrificial templates to 

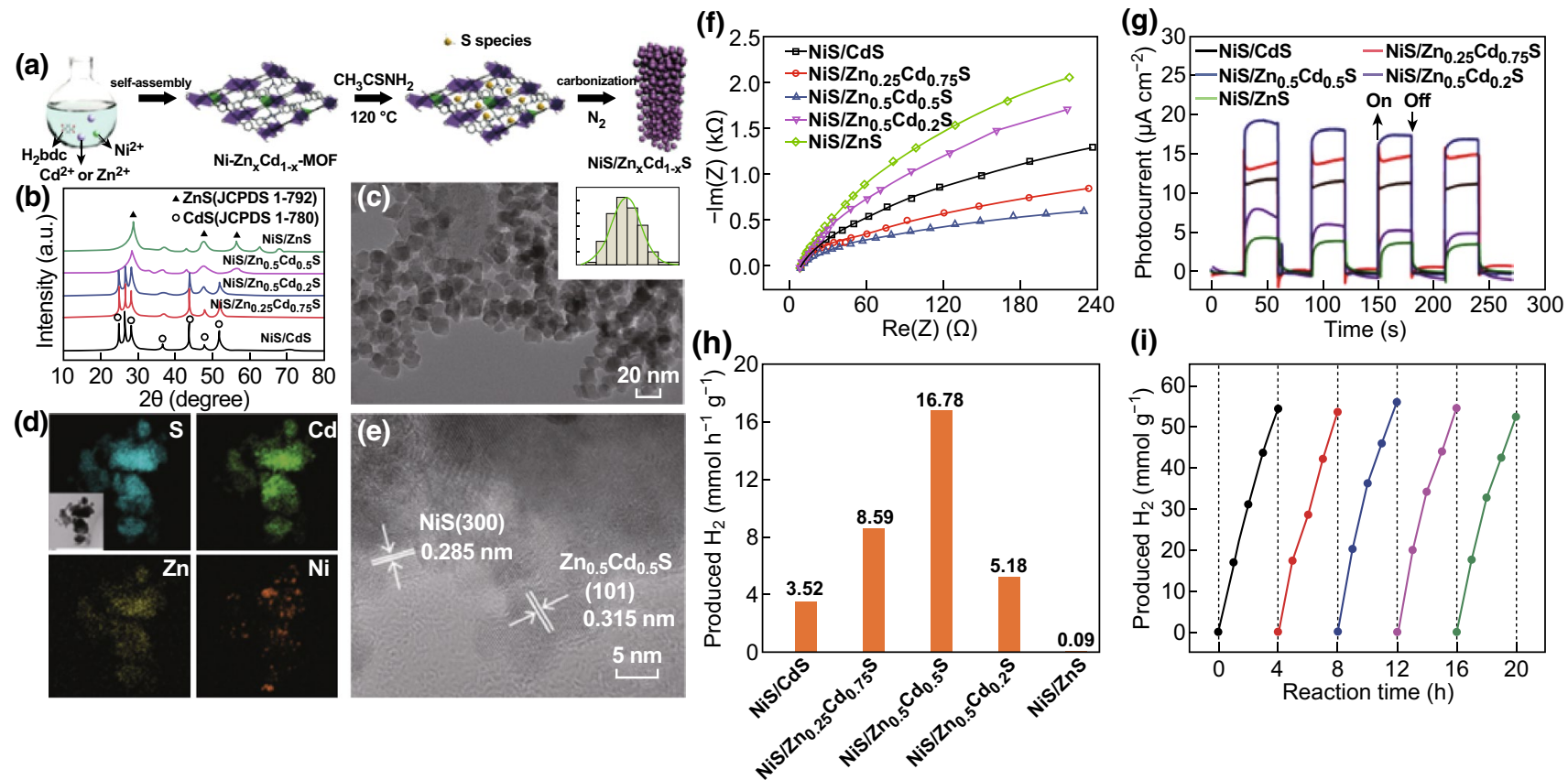

Fig. 5 a Schematic illustration of the synthetic procedure for $\mathrm{NiS} / \mathrm{Zn}_{x} \mathrm{Cd}_{1-x} \mathrm{~S}$. b PXRD patterns of $\mathrm{NiS} / \mathrm{Zn}_{x} \mathrm{Cd}_{1-x} \mathrm{~S}$. c TEM image and particle size distribution (Fig. $2 \mathrm{c}$ inset) of NiS/ $\mathrm{Zn}_{0.5} \mathrm{Cd}_{0.5} \mathrm{~S}$. d EELS elemental mapping images and e HRTEM image of NiS/Zn ${ }_{0.5} \mathrm{Cd}_{0.5} \mathrm{~S}$. f EIS plots, $\mathbf{g}$ photocurrent-time dependence, and $\mathbf{h}$ comparison of photocatalytic HER rates of $\mathrm{NiS} / \mathrm{Zn}_{x} \mathrm{Cd}_{1-x} \mathrm{~S}$; $\mathbf{i}$ HER cycling test for $\mathrm{NiS} / \mathrm{Zn}_{0.5} \mathrm{Cd}_{0.5} \mathrm{~S}$ under visible-light irradiation. Reprinted with permission from Ref. [72]

form the $\mathrm{NiS} / \mathrm{Zn}_{x} \mathrm{Cd}_{1-x} \mathrm{~S}$ series via solvothermal sulfidation and thermal annealing. By adjusting the doping metal concentration in the MOFs, the chemical compositions and band gaps of the heterojunctions were fine-tuned, leading to an optimized HER rate of up to $16,780 \mu \mathrm{mol}(\mathrm{g} \mathrm{h})^{-1}$ with NiS/ $\mathrm{Zn}_{0.5} \mathrm{Cd}_{0.5} \mathrm{~S}$ as the photocatalyst under visible-light irradiation. In-depth DFT calculations revealed the importance of $\mathrm{NiS}$ in accelerating the water dissociation kinetics, which was crucial for photocatalytic HER. Notably, a visible-light catalytic system with a HER rate of up to $17,360 \mu \mathrm{mol}$ $(\mathrm{g} \mathrm{h})^{-1}$ over a Co- $\mathrm{Zn}_{0.5} \mathrm{Cd}_{0.5} \mathrm{~S}$ solid solution catalyst was developed via a sulfidation process of $\mathrm{Co} / \mathrm{Zn}-\mathrm{ZIF}$ in the presence of $\mathrm{Cd}^{2+}$ [90]. The doping of Co evenly around the skeleton of the porous $\mathrm{Zn}_{0.5} \mathrm{Cd}_{0.5} \mathrm{~S}$ solid solution played an important role in improving the photocatalytic activity, as compared to that of $\mathrm{Zn}_{0.5} \mathrm{Cd}_{0.5} \mathrm{~S}$, which displayed a HER rate of $12,130 \mu \mathrm{mol}(\mathrm{g} \mathrm{h})^{-1}$ under the same reaction condition.

As per the reports mentioned above, utilizing MOFs as templates or precursors to construct heterojunctions between a semiconductor material and another semiconductor material or a noble metal material is an effect way to improve the performance of semiconductors in photocatalytic HER by water splitting. Accordingly, Li et al. reported a series of $\mathrm{Zn} /$ Co-ZIF derivative/Pt photocatalytic systems, which exhibited high performance toward the photocatalytic HER under UV-Vis light (shown in Fig. 6) [65]. The synthesis processes involved the oxidation, sulfurization, or phosphorization of $\mathrm{ZnCo}-\mathrm{ZIF}$, and the subsequent photochemical doping of $\mathrm{Pt}$ nanoparticles, leading to $\mathrm{Pt}-\mathrm{ZnO}-\mathrm{Co}_{3} \mathrm{O}_{4}, \mathrm{Pt}-\mathrm{ZnS}-\mathrm{CoS}$, and $\mathrm{Pt}-\mathrm{Zn}_{3} \mathrm{P}_{2}-\mathrm{CoP}$, respectively. The porous framework skeleton of the $\mathrm{ZnCo}-\mathrm{ZIF}$ derivatives significantly enhanced the light utilization and simultaneously afforded abundant exposed catalytic active sites; the suitable band matching and strong electron coupling in the heterojunctions facilitated efficient electron-hole separation and transportation; the distribution of Pt nanoparticles on the porous structure offered enough redox active sites. These beneficial features were revealed to be responsible for the highly enhanced performances of the $\mathrm{Zn} / \mathrm{Co}-\mathrm{ZIF}$ derivative/Pt photocatalysts. This bimetallic MOF-directed fabrication strategy reported in this paper provided a new perspective to construct synergetic photocatalysts with excellent photocatalytic performances for water-splitting applications. 

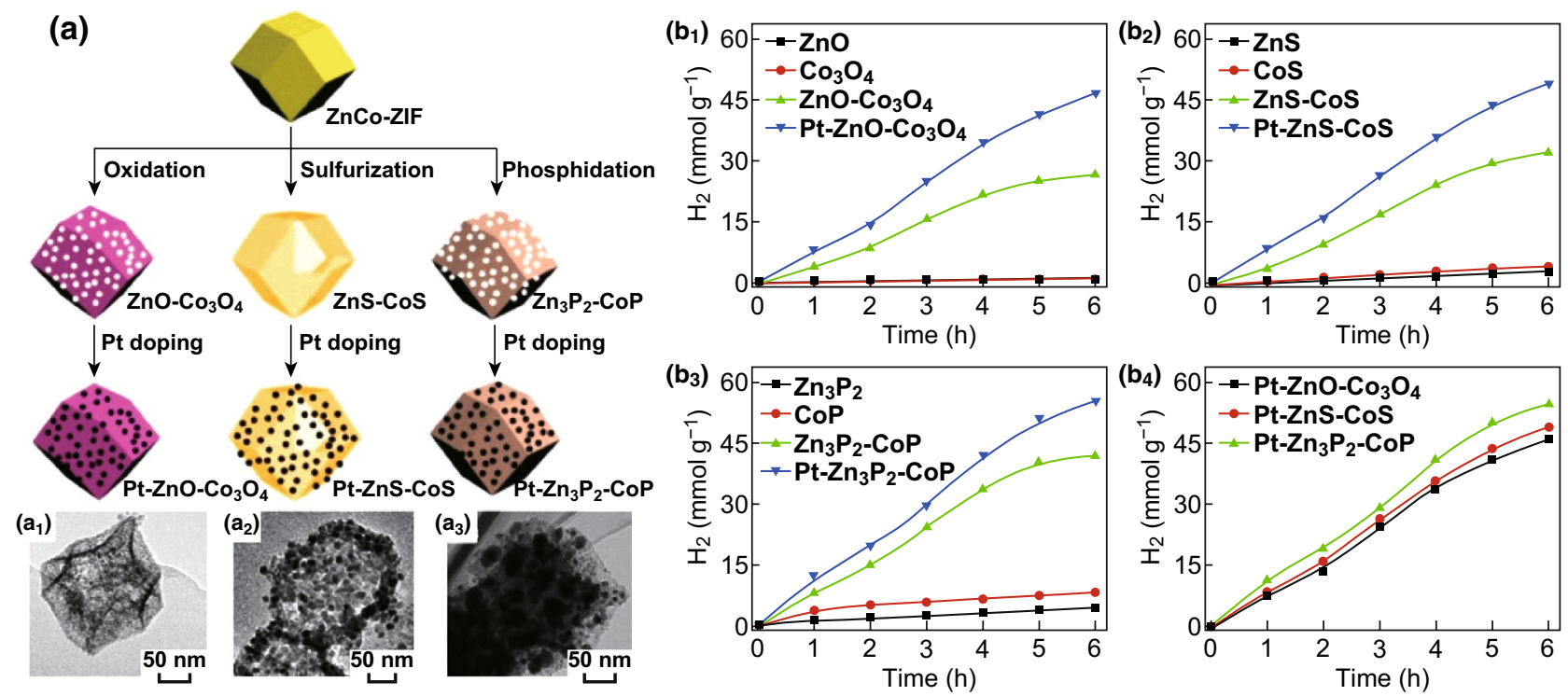

Fig. 6 a Schematic illustration of the fabrication of $\mathrm{Pt}-\mathrm{ZnO}-\mathrm{Co}_{3} \mathrm{O}_{4}, \mathrm{Pt}-\mathrm{ZnS}-\mathrm{CoS}$, and $\mathrm{Pt}-\mathrm{Zn}_{3} \mathrm{P}_{2}-\mathrm{CoP}$ photocatalysts. $\mathbf{a}_{1}-\mathbf{a}_{3}$ TEM images of $\mathrm{Pt}-\mathrm{ZnO}-\mathrm{Co}_{3} \mathrm{O}_{4}, \mathrm{Pt}-\mathrm{ZnS}-\mathrm{CoS}$, and $\mathrm{Pt}-\mathrm{Zn}_{3} \mathrm{P}_{2}-\mathrm{CoP} . \mathbf{b}_{\mathbf{1}}-\mathbf{b}_{\mathbf{4}}$ Photocatalytic hydrogen generation as the function of reaction time over different photocatalysts. Reprinted with permission from Ref. [65]
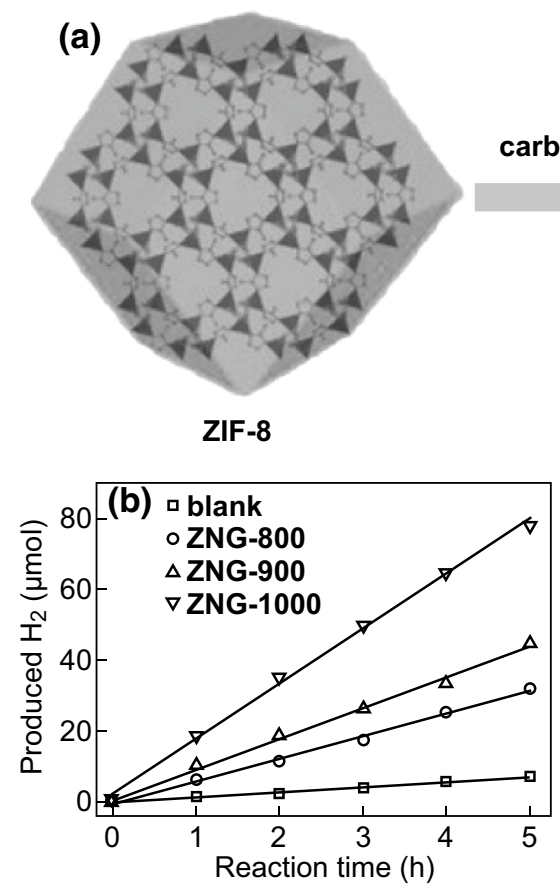

\section{carbonization}

$\operatorname{Ar}$

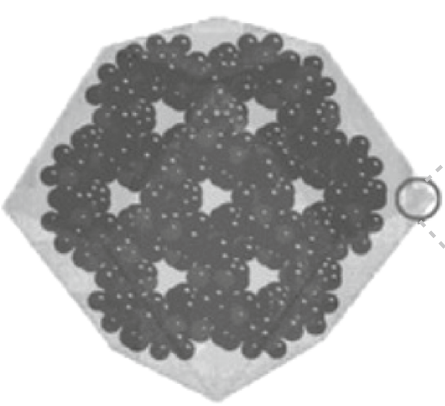

ZNG

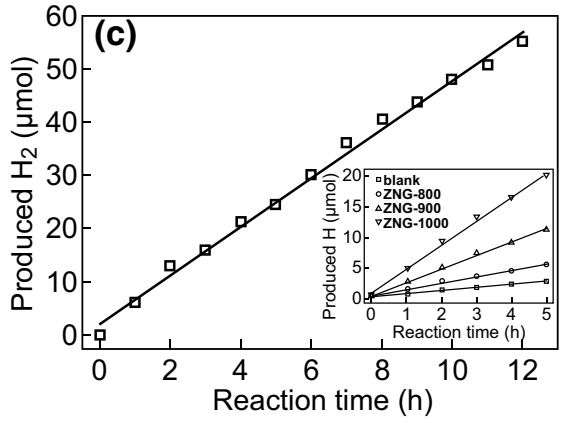

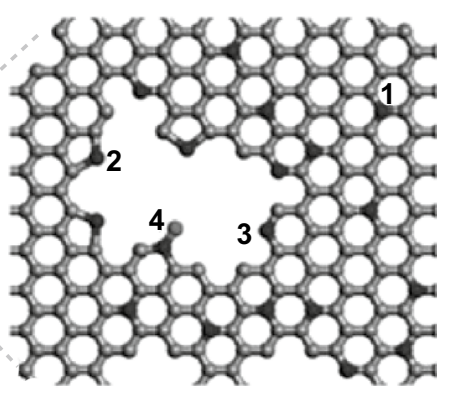

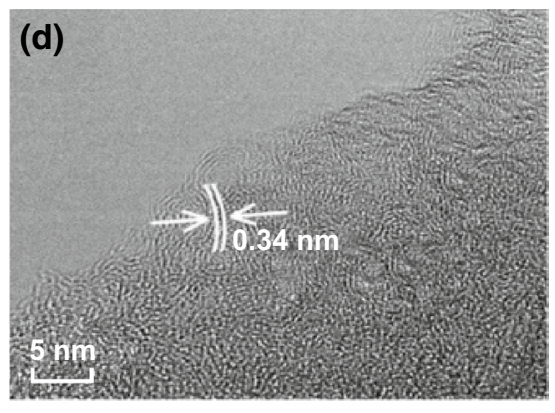

Fig. 7 a Schematic illustration of the synthetic procedure of ZNGs and four types of bonding configurations of $\mathrm{N}$ atoms (1 graphitic N, 2 pyrrolic N, 3 pyridinic N, 4 pyridine- $N$-oxide). b Photocatalytic activities of $\mathrm{ZNGs}$ for $\mathrm{H}_{2}$ production with Pt as a cocatalyst. $\mathbf{c}$ Photocatalytic activity of ZNG-1000 under a prolonged light illumination for $12 \mathrm{~h}$ without Pt as a cocatalyst (inset: time course of the $\mathrm{H}_{2}$ evolution rate of ZNGs without Pt as a cocatalyst). d High-resolution TEM image of ZNG-1000. Reproduced with permission from Ref. [58] 


\subsubsection{MOF-Derived Porous Carbon Materials}

In general, progress on the photocatalytic hydrogen evolution from water over MOFs-derived photocatalysts have been made mainly around metal-involving materials, like metal oxides, metal sulfides, or their composites, which are commonly used in the photocatalytic field. As alternatives, metal-free photocatalysts, such as carbon-based materials, demonstrating great performance are highly desired, due to their tunable molecular structures, abundance, and high chemical stability. Meanwhile, facile synthesis of metal-free photocatalysts is still highly challenging. Cheng and coworkers have developed a facile synthesis method for N-doped graphene carbon using a well-designed ZIF-8-template (Fig. 7) [58]. Under an Ar atmosphere at different temperatures, ZIF-8 were calcined to derive $\mathrm{N}$-doped graphene (ZNG) analogs, which retained the polyhedron structure of the parent ZIF-8 particles and had nitrogen contents of 9-15 wt \%; the contents of various $\mathrm{N}$ types in the materials were fine-tuned on the basis of the calcination temperatures. Among them, the product obtained at $1000{ }^{\circ} \mathrm{C}$ exhibited the best performance toward photocatalytic HER because of the highest content of graphitic nitrogen, which preserved the high mobility of the charge carriers and further affected the hydrogen evolution rate of the photocatalyst.

\subsection{Photocatalytic Water Oxidation}

Water oxidation to $\mathrm{O}_{2}$ is regarded as the bottleneck of solardriven water splitting, ascribed to the intrinsic difficulty in multiple-electron transfer and sluggish kinetics of the subsequent oxygen evolution [97, 98]. Although some noble metals and their oxides, such as $\mathrm{IrO}_{2}$ and $\mathrm{RuO}_{2}$, have attracted much attention as efficient catalysts for water oxidation, their high cost and low abundance have impeded their commercial utilization. Therefore, first-row transition metal oxides and their derivatives, including cobalt oxides, iron oxides, nickel oxides, and manganese oxides, have been explored as water oxidation catalysts due to advantages with regard to economy and stability [99-105]. In the water oxidation reaction system (i.e., OER), the reduction of sacrificial oxidants, such as $\mathrm{AgNO}_{3}$ and $\mathrm{Na}_{2} \mathrm{~S}_{2} \mathrm{O}_{8}$, is normally used to replace the half-reaction of HER [77].

According to investigations, MOF-derived water oxidation photocatalysts, particularly cobalt oxide-based systems, are environmentally benign, thermally stable, inexpensive, and demonstrate high OER activity both in the electrochemical and in the photochemical fields. The Lu group developed a facile approach for the preparation of a porous cobalt oxide-carbon hybrid as a water oxidation catalyst by carbonizing nanocrystals of ZIF-67 in an inert atmosphere and subsequently air-calcining them [92]. Among the various $\mathrm{CoO}_{x} / \mathrm{C}$ hybrids obtained at different calcination temperatures, $700-\mathrm{CoO}_{x} / \mathrm{C}$ acted as the best catalyst. The photocatalytic activity of $700-\mathrm{CoO}_{x} / \mathrm{C}$ was accessed in the $\left[\mathrm{Ru}(\mathrm{bpy})_{3}\right]^{2+}-\mathrm{S}_{2} \mathrm{O}_{8}{ }^{2-}$ system under visible light in a sodium phosphate buffer ( $\mathrm{pH} 8.5$ ) and a maximum turnover frequency (TOF) of up to $0.039 \pm 0.03 \mathrm{~s}^{-1}$ per cobalt atom was estimated, which was among the highest TOFs for water oxidation with cobalt oxide-based photocatalysts.

Furthermore, by combining ZIF-67 with suitable materials as precursors, adjustable cobalt oxide-based composites as photocatalysts for water oxidation could be fabricated. For example, the derivatives obtained by loading a single Keggin-type polyoxometalate (POM) cluster into each confined space of ZIF-67, i.e., POM@ $\mathrm{Co}_{3} \mathrm{O}_{4}$ composites (CW$n, n$ depended on the added amount of POM) doped with highly dispersive molecular metal-oxo clusters, exhibited significantly improved photocatalytic activity in water oxidation compared to the pure MOF-derived nanostructure (as shown in Fig. 8) [93]. In the molecular cluster@ oxide system, POMs accept and release electrons, thereby improving the separation of light-induced electrons and holes, which leads to higher catalytic activity with increasing POM concentration in the composite materials. Ding's group synthesized a series of $\mathrm{Co}_{3} \mathrm{O}_{4} / \mathrm{CuO}$ hollow polyhedral nanocages (HPNC) using ZIF-67/Cu hydroxide (HD) polyhedrons with various $\mathrm{Co} / \mathrm{Cu}$ molar ratios as sacrificial templates [68]. With an optimized $\mathrm{Co} / \mathrm{Cu}$ molar ratio, $\mathrm{Co}_{3} \mathrm{O}_{4} / \mathrm{CuO}-3 \mathrm{HPNCs}$ afforded a high TOF of $4.9 \times 10^{-3} \mathrm{~s}^{-1}$ per metal atom and performed well in the stability test.

In addition, Prussian blue analogue (PBA), a type of crystalline MOF built from divalent and trivalent metal ions (such as $\mathrm{Fe}, \mathrm{Co}$, and $\mathrm{Ni}$ ) linked by cyanide ligands, has also been chosen as the precursor to fabricate water oxidation photocatalysts, such as $\mathrm{Fe} / \mathrm{Co} / \mathrm{Ni}$-oxides and their solid solutions. Ding's group reported the use of low-cost porous iron-based oxides derived from the calcination of PBA $\left(\mathrm{M}_{x}\left[\mathrm{Fe}(\mathrm{CN})_{6}\right]_{\mathrm{y}}\right.$, where $\left.\mathrm{M}=\mathrm{Fe}, \mathrm{Co}, \mathrm{Ni}\right)$ and porous Co-based oxide nanocages derived from the calcination of PBA $\left(\mathrm{M}_{x}\left[\mathrm{Co}(\mathrm{CN})_{6}\right]_{\mathrm{y}}\right.$, where $\mathrm{M}=\mathrm{Fe}, \mathrm{Co}$, and $\left.\mathrm{Mn}\right)$ as catalysts in photocatalytic water oxidation [94, 95]. The 

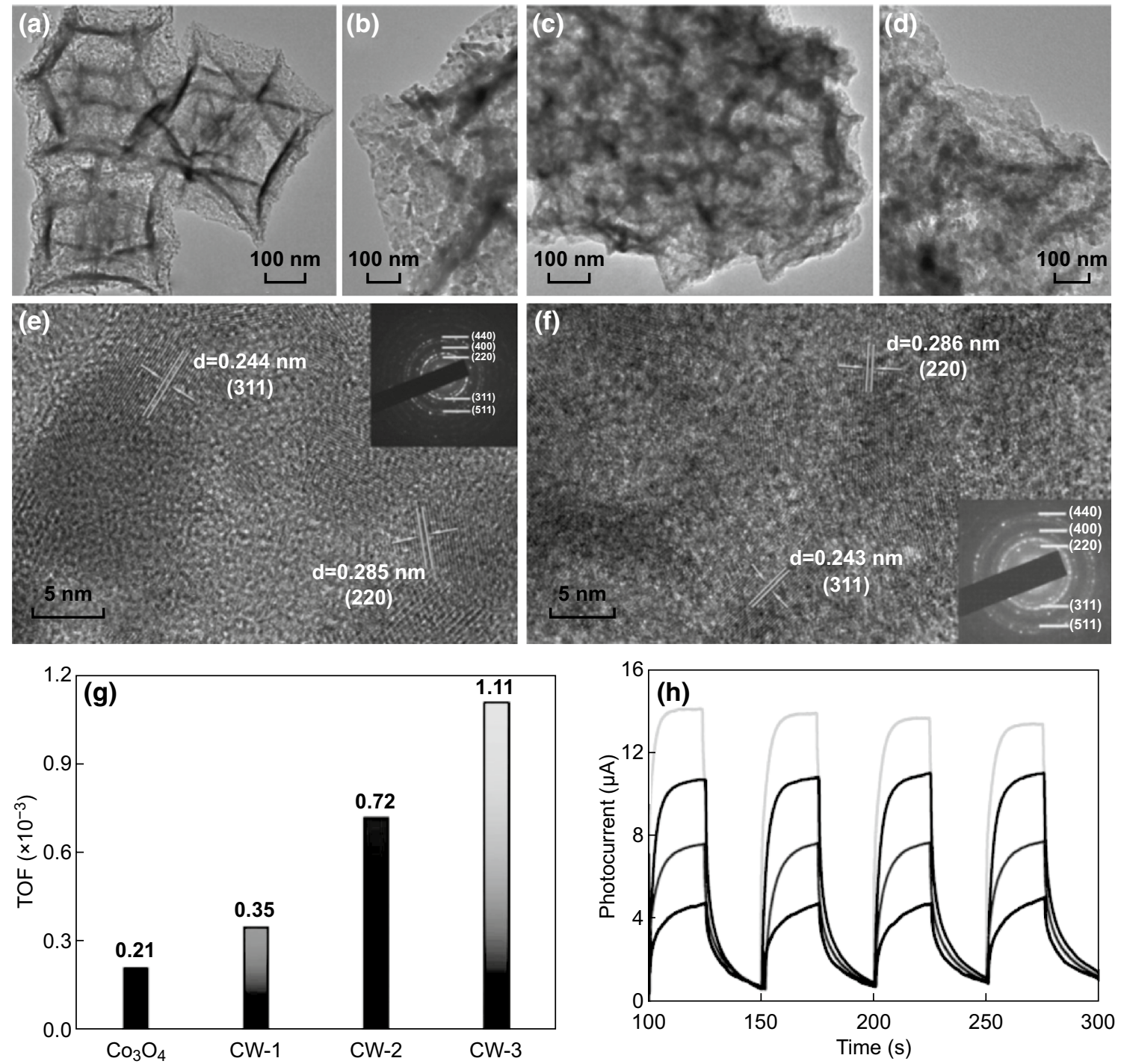

Fig. 8 a Low- and $\mathbf{b}$ high-magnification TEM images of $\mathrm{Co}_{3} \mathrm{O}_{4}$ hollow dodecahedra. $\mathbf{c}$ Low- and $\mathbf{d}$ high-magnification TEM images of CW-2 hollow dodecahedra. e HRTEM image of $\mathrm{Co}_{3} \mathrm{O}_{4}$ hollow dodecahedra (inset is the SAED pattern recorded for the whole particle). $\mathbf{f}$ HRTEM image of CW-2 hollow dodecahedra (inset is the SAED pattern recorded from the whole particle). $\mathbf{g}$ TOF and $\mathbf{h}$ transient photocurrent response of $\mathrm{Co}_{3} \mathrm{O}_{4}$ and $\mathrm{CW}-n$ under visible-light irradiation (from left to right: $\mathrm{Co}_{3} \mathrm{O}_{4}, \mathrm{CW}-1, \mathrm{CW}-2$, and $\mathrm{CW}-3$ ). Reprinted with permission from Ref. [93]

obtained series of Fe photocatalysts followed the order of $\mathrm{Co}_{x} \mathrm{Fe}_{3-x} \mathrm{O}_{4}>\mathrm{Ni}_{x} \mathrm{Fe}_{3-x} \mathrm{O}_{4}>\mathrm{Fe}_{2} \mathrm{O}_{3}$, and $\mathrm{Co}_{x} \mathrm{Fe}_{3-x} \mathrm{O}_{4}$ afforded an initial TOF of $5.4 \times 10^{-4} \mathrm{~s}^{-1}$ per transition metal atom. Meanwhile, the obtained series of Co photocatalysts followed the order of $\mathrm{Co}_{3} \mathrm{O}_{4}>\mathrm{Mn}_{x} \mathrm{Co}_{3-x} \mathrm{O}_{4}>\mathrm{Fe}_{x} \mathrm{Co}_{3-x} \mathrm{O}_{4}$, and $\mathrm{Co}_{3} \mathrm{O}_{4}$ porous nanocages exhibited the highest TOF of $3.2 \times 10^{-4} \mathrm{~s}^{-1}$ per Co atom.

In summary, tremendous efforts have been devoted to develop efficient photocatalysts toward water splitting with MOFs or their hybrids as the precursors, and great progress has been made in this regard. However, the currently developed photocatalytic systems based on MOF-derived porous structures only involve one isolated half-reaction, and sacrificial reagents are needed to replace the other half-reaction. More studies have been performed on hydrogen evolution reaction than oxygen evolution reaction due to the intrinsic difficulty associated with OER in multiple-electron transfer and sluggish kinetics. However, the practical application of water splitting demands the production of stoichiometric amounts of $\mathrm{H}_{2}$ and $\mathrm{O}_{2}$ driven by sunlight without any 
sacrificial reagents. Therefore, photocatalytic overall watersplitting systems with high efficiency are highly desired. Moreover, the porous structures of photocatalysts can influence the attachment of gas bubbles on the surface of the catalysts, which can potentially block the active sites and prohibit mass transportation under strong gas evolution conditions, leading to bubble overpotential [106]. As far as we know, no investigation on the influence of pore structure of MOFs-derived photocatalysts on overpotential for watersplitting reaction, especially OER, has been performed, and therefore, further studies are needed.

\section{Photocatalytic $\mathrm{CO}_{2}$ Reduction}

The global climate issues caused by the rapidly increasing $\mathrm{CO}_{2}$ emissions have accelerated studies on photocatalytic $\mathrm{CO}_{2}$ reduction to $\mathrm{CO}$ or hydrocarbons, which can not only decrease the $\mathrm{CO}_{2}$ level in the atmosphere, facilitating environmental protection, but also generate materials for chemical industry or energy storage. Nowadays, the photocatalytic $\mathrm{CO}_{2}$ reduction process is attracting growing attention because of its usage of solar power as the primary energy source. Photocatalytic $\mathrm{CO}_{2}$ reduction involves the following steps: light harvesting, separation, transfer of photogenerated charge carriers, as well as adsorption and conversion of $\mathrm{CO}_{2}$ [107]. Therefore, in addition to the impacts of light utilization, charge transfer efficiency, and active sites, the adsorption of $\mathrm{CO}_{2}$ is another important factor to expedite the $\mathrm{CO}_{2}$ reduction process in a photocatalytic system. The $\mathrm{CO}_{2}$ reduction products include $\mathrm{HCOOH}, \mathrm{CO}, \mathrm{HCHO}$, $\mathrm{CH}_{3} \mathrm{OH}$, and $\mathrm{CH}_{4}$. MOF-derived materials are considered highly potential photocatalysts for $\mathrm{CO}_{2}$ reduction due to their advantages such as structural and compositional variety and high surface areas. Some excellent works have been reported on MOF-derived materials as $\mathrm{CO}_{2}$ reduction photocatalysts (Table 3).

Ye's group developed a MIL-101-derived Fe@C catalyst, consisting of an iron core $(<10 \mathrm{~nm})$ and ultrathin (1-3 layers) carbon layers, for the photocatalytic reduction of $\mathrm{CO}_{2}$ to $\mathrm{CO}$ [108]. The obtained Fe @ C photocatalysts could produce $2196.17 \mu \mathrm{mol} C O$ under broadband light irradiation for $120 \mathrm{~min}$, which was better than that reported for most of the catalysts. Through a thorough investigation, they found that the intense adsorption of visible light and infrared radiation induced a thermal effect, which helped to drive the reaction, and UV-light-induced iron local surface-plasmon resonances also played a significant role in activating the nonpolar $\mathrm{CO}_{2}$ molecules. Furthermore, DFT calculations revealed that the ultrathin layers of carbon shells on the Fe nanoparticles dramatically promoted desorption of the produced $\mathrm{CO}$ from the catalyst surface, thereby increasing the $\mathrm{CO}$ selectivity (99.76\%). Another study on the photocatalytic $\mathrm{CO}_{2}$ reduction to $\mathrm{CO}$ with MOF-derived materials as catalysts was reported by Lou's group; they rationally fabricated hierarchical $\mathrm{In}_{2} \mathrm{~S}_{3}-\mathrm{CdIn}_{2} \mathrm{~S}_{4}$ heterostructured nanotubes via sequential ion exchange reactions with MIL-68 as the initial precursor (Fig. 9) [74]. Benefiting from the unique structural and compositional features, such as nanosized interfacial contacts between $\operatorname{In}_{2} \mathrm{~S}_{3}$ and $\mathrm{CdIn}_{2} \mathrm{~S}_{4}$ nanospecies, reduced diffusion length for charge carrier separation and migration, large surface area for $\mathrm{CO}_{2}$ adsorption and concentration, and rich catalytically active sites for surface redox reactions, the obtained hierarchical $\mathrm{In}_{2} \mathrm{~S}_{3}-\mathrm{CdIn}_{2} \mathrm{~S}_{4}$ nanotubes manifested an optimized $\mathrm{CO}$ generation rate under visible light. Very recently, a three-component heterojunction $\mathrm{C}-\mathrm{Cu}_{2-x} \mathrm{~S} @ \mathrm{~g}$ $\mathrm{C}_{3} \mathrm{~N}_{4}$ photocatalyst was found to be active toward the reduction of $\mathrm{CO}_{2}$ to $\mathrm{CO}$. With MOF-199 as the precursor, hollow tubular $\mathrm{Cu}_{2-x} \mathrm{~S}$ with carbon coating was successfully

Table 3 Selected MOF derivatives that serve as photocatalysts for $\mathrm{CO}_{2}$ reduction

\begin{tabular}{|c|c|c|c|c|c|c|c|}
\hline Photocatalyst & MOF precursors & $E_{\mathrm{g}}(\mathrm{eV})$ & Illumination range & Main products & $\begin{array}{l}\text { Reaction rate } \\
\left(\mu \mathrm{mol}(\mathrm{g} \mathrm{h})^{-1}\right)\end{array}$ & $\begin{array}{l}\text { Recycled } \\
\text { times }\end{array}$ & $\begin{array}{l}\text { Refer- } \\
\text { ences }\end{array}$ \\
\hline $\mathrm{Fe} @ \mathrm{C}$ & MIL-101 & - & UV-Vis light & $\mathrm{CO}$ & 18,301 & 5 & {$[108]$} \\
\hline $\mathrm{ZnMn}_{2} \mathrm{O}_{4}$ & $\mathrm{Zn} / \mathrm{Mn}-\mathrm{MOF}$ & 2.51 & UV-Vis light & $\mathrm{CO}$ & 23.99 & - & [111] \\
\hline $\mathrm{In}_{2} \mathrm{~S}_{3} / \mathrm{CdIn}_{2} \mathrm{~S}_{4}$ & MIL-68 & 2.21 & Visible light & $\mathrm{CO}$ & 825 & 6 & [74] \\
\hline $\mathrm{C}-\mathrm{Cu}_{2-x} \mathrm{~S} @ \mathrm{~g}-\mathrm{C}_{3} \mathrm{~N}_{4}$ & MOF-199 & - & Visible light & $\mathrm{CO}$ & 88.55 & - & [109] \\
\hline $\mathrm{ZnO} / \mathrm{NiO}$ & $\mathrm{Zn} / \mathrm{Ni}-\mathrm{MOF}$ & - & UV-Vis light & $\mathrm{CH}_{3} \mathrm{OH}$ & 1.57 & - & {$[64]$} \\
\hline $\mathrm{Au} / \mathrm{TiO}_{2}$ & Au/MIL-125 & - & UV light & $\mathrm{CH}_{4}$ & $240^{\mathrm{a}}$ & 2 & {$[110]$} \\
\hline
\end{tabular}

${ }^{\mathrm{a}}$ Unit: ppm $(\mathrm{g} \mathrm{h})^{-1}$ 
(a)

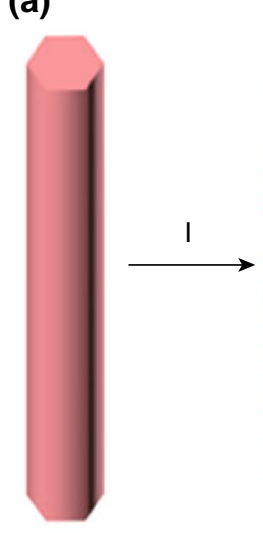

MIL-68 prism

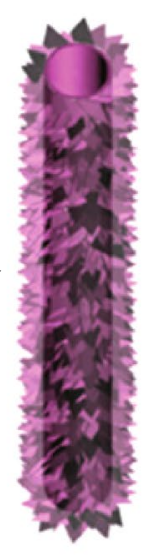

$\ln _{2} \mathbf{S}_{3}$ nanotube

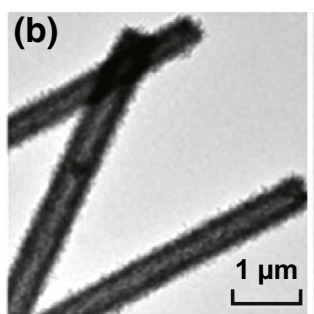

(e)
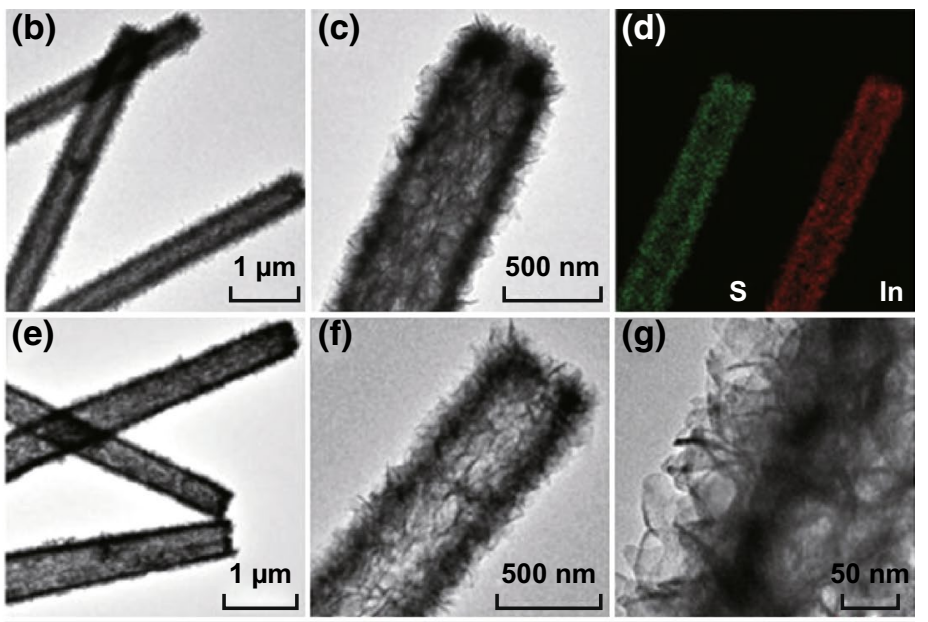

(h)

$\ln _{2} S_{3}-C_{d l n} S_{4}$ nanotube
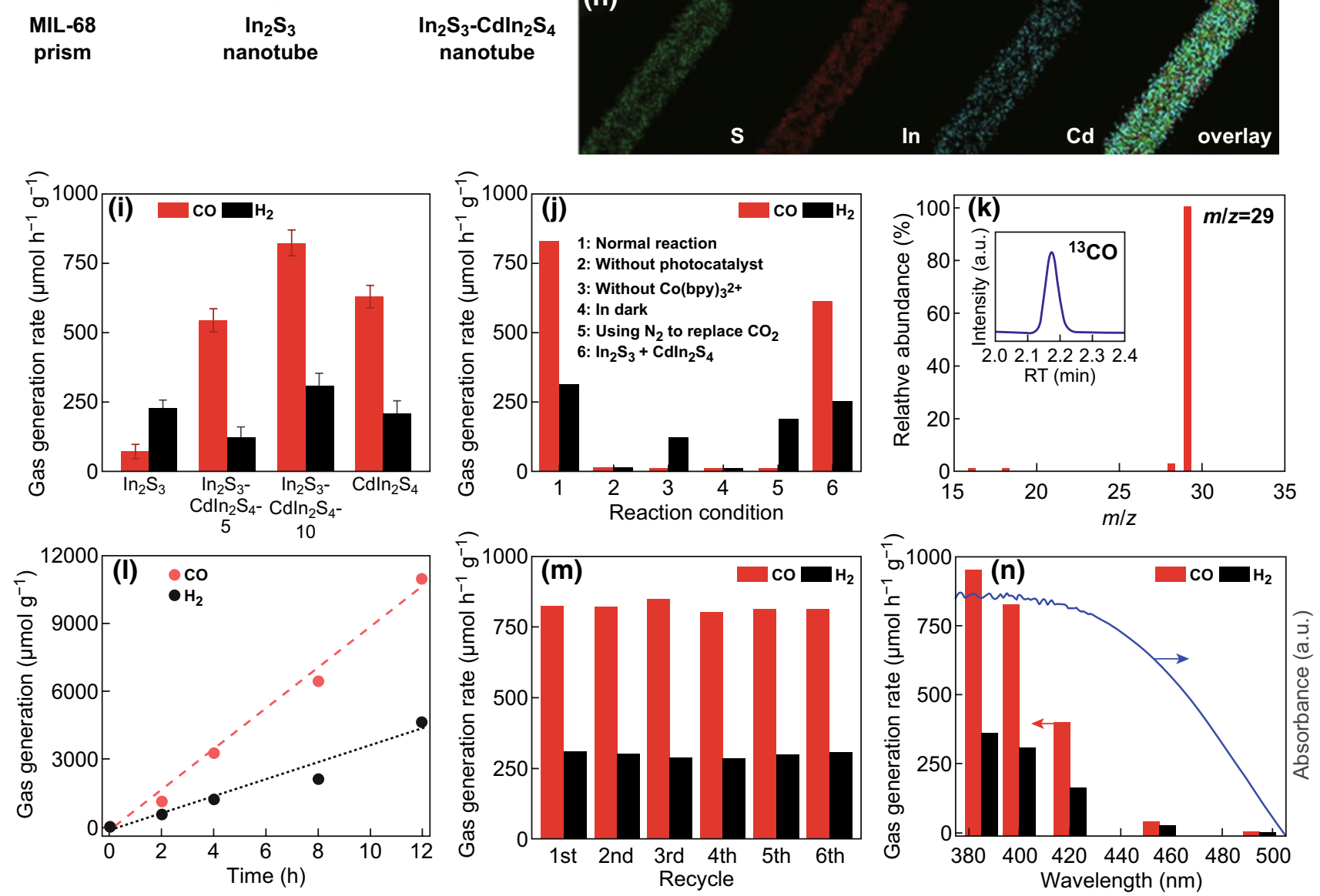

Fig. 9 a Schematic illustration of the synthetic process of the hierarchical $\operatorname{In}_{2} \mathrm{~S}_{3}-\mathrm{CdI}_{2} \mathrm{~S}_{4}$ heterostructured nanotube: (I) liquid phase sulfidation and (II) cation exchange reaction. b, c TEM images of hierarchical $\mathrm{In}_{2} \mathrm{~S}_{3}$ nanotubes. $\mathbf{d}$ Elemental mappings of an individual $\mathrm{In}_{2} \mathrm{~S}_{3}$ nanotube. e-g TEM images of hierarchical $\operatorname{In}_{2} \mathrm{~S}_{3}-\mathrm{CdIn}_{2} \mathrm{~S}_{4}-10$ nanotubes. h Elemental mappings of a single $\operatorname{In}_{2} \mathrm{~S}_{3}-\mathrm{CdIn}_{2} \mathrm{~S}_{4}-10$ nanotube. i-n CO tion performance. $\mathbf{i}$ Generation of $\mathrm{CO}$ and $\mathrm{H}_{2}$ over different samples. $\mathbf{j}$ Evolution of $\mathrm{CO}$ and $\mathrm{H}_{2}$ under various reaction conditions. $\mathbf{k}$ Results of GC-MS analysis of $\mathrm{CO}$ produced from ${ }^{13} \mathrm{CO}_{2}$ isotope experiment. 1 Production of $\mathrm{CO}$ and $\mathrm{H}_{2}$ as a function of reaction time. $\mathbf{m}$ Formation of CO and $\mathrm{H}_{2}$ in stability tests. $\mathbf{n}$ Wavelength dependence of yields of $\mathrm{CO}$ and $\mathrm{H}_{2}$, and the light absorption spectrum of $\operatorname{In}_{2} \mathrm{~S}_{3}-\mathrm{CdIn} \mathrm{S}_{2}-10$ photocatalyst. Reprinted with the permission from Ref. [74] 
fabricated, and further, different amounts of the material were loaded on $\mathrm{g}_{-} \mathrm{C}_{3} \mathrm{~N}_{4}$ to form a series of $\mathrm{C}-\mathrm{Cu}_{2-x} \mathrm{~S} @ \mathrm{~g}$ $\mathrm{C}_{3} \mathrm{~N}_{4}$ photocatalysts. Under visible-light irradiation and water vapor condition, the optimized $\mathrm{C}-\mathrm{Cu}_{2-x} \mathrm{~S} @ \mathrm{~g}-\mathrm{C}_{3} \mathrm{~N}_{4}$ with $0.71 \mathrm{wt} \%$ of $\mathrm{C}-\mathrm{Cu}_{2-x} \mathrm{~S}$ exhibited a high reactivity of $1062.6 \mu \mathrm{mol} \mathrm{g}{ }^{-1}$ and selectivity of $97 \%$ [109].

Photocatalytic reduction of $\mathrm{CO}_{2}$ to hydrocarbons by water vapor with proper catalysts has also been taken into account. Fischer and coworkers have fabricated an $\mathrm{Au} \mathrm{NP} / \mathrm{TiO}_{2}$ $\left(\mathrm{GNP} / \mathrm{TiO}_{2}\right)$ photocatalyst active for the reduction of $\mathrm{CO}_{2}$ to $\mathrm{CH}_{4}$ [110]. After deposition of preformed and surfactant-stabilized gold nanoparticles on the surface of $\mathrm{NH}_{2}$-MIL-125, GNP/ $/ \mathrm{NH}_{2}$-MIL-125 was transformed to GNP/TiO 2 through a thermal treatment; the product contained rutile $\mathrm{TiO}_{2}$ and possessed the morphology of $\mathrm{NH}_{2}$-MIL-125. Compared with the $\mathrm{TiO}_{2}$ sample obtained via the pyrolysis of $\mathrm{NH}_{2}$-MIL-125 without GNP, P25, and commercial $\mathrm{Au} / \mathrm{TiO}_{2}$, the GNP/ $\mathrm{TiO}_{2}$ photocatalyst delivered a significantly higher yield of $\mathrm{CH}_{4}$ due to the presence of GNP. Metal oxide composites obtained with MOFs as precursors were also utilized as catalysts for the photocatalytic reduction of $\mathrm{CO}_{2}$ to hydrocarbons by Zhang's group [64]. They fabricated a series of $\mathrm{ZnO} /$ $\mathrm{NiO}$ porous hollow spheres with sheet-like subunits through the calcination of bimetallic $\mathrm{Zn} / \mathrm{Ni}-\mathrm{MOF}$ s with different ratios of $\mathrm{Zn} / \mathrm{Ni}$. The $\mathrm{p}-\mathrm{n}$ heterojunctions formed by $\mathrm{p}$-type $\mathrm{ZnO}$ and n-type $\mathrm{NiO}$, and the hollow character enhanced the performance of $\mathrm{ZnO} / \mathrm{NiO}$ composites by facilitating the separation of the photogenerated hole-electron carriers. As a result, the optimized $\mathrm{ZnO} / \mathrm{NiO}$ composites (ZN-30) acted three times better than pure $\mathrm{ZnO}$ in the photocatalytic reduction of $\mathrm{CO}_{2}$ to $\mathrm{CH}_{3} \mathrm{OH}$.

To date, despite the high potential in sustainability and energy storage, only few studies have been focused on the photocatalytic reduction of $\mathrm{CO}_{2}$ with MOF-derived materials as catalysts. Therefore, more progress should be made on developing more efficient photocatalysts that can enhance the utilization of solar energy and perform better, in terms of both the activity and selectivity.

\section{Photocatalytic Organic Reaction}

The photocatalytic synthesis of organic compounds is a promising approach due to its mild, clean and atom efficiency methodologies, compared with the methods involving high temperature and pressure, and the current industrial synthetic strategies, which generate harmful by-products [112]. Photoinduced charge carriers transferred from semiconductor nanomaterials to organic molecules can catalytically trigger a variety of organic redox reactions. Recently, functionalized MOFs have served as interesting photocatalysts for various organic redox reactions due to their unique, tailorable, and highly porous characteristics. However, the poor thermal stability of MOFs hampers their commercialized utilization [51]. On the other hand, MOF-derived semiconductors, which can inherit the porous structure and diversity in structure from parent MOFs, as photocatalysts, have the advantages of high surface areas, high stability, and controllable band gaps, which can match the different HOMO-LUMO positions of the organic molecules. The photocatalytic mechanism of organic redox reaction shares similar process with other photocatalytic systems, i.e., light adsorption, separation and transfer of photoinduced charge carriers, and the subsequent redox reactions on the surfaceactive sites of the photocatalysts. In Table 4, some examples of MOF-derived porous structures exhibiting high performance in visible-light-driven photoredox catalysis are given.

Long-lived photogenerated carriers play an important role in improving the activity of photocatalysts. Multiple strategies, including structural engineering, semiconductor compositing, doping and so on, have been developed to enhance the transfer and separation efficiency of electrons and holes. The facile method with MOFs as the templates and precursors has been proven ideal for engineering photocatalysts

Table 4 Selected MOF derivatives that serve as photocatalysts for organic reactions

\begin{tabular}{|c|c|c|c|c|c|c|c|}
\hline Photocatalyst & MOF precursors & Illumination range & Reaction type & Time (h) & Yield (\%) & $\begin{array}{l}\text { Recycled } \\
\text { times }\end{array}$ & $\begin{array}{l}\text { Refer- } \\
\text { ences }\end{array}$ \\
\hline N-doped $\mathrm{Cu}_{2} \mathrm{O} @ \mathrm{~N}-\mathrm{C}$ & NTU-105 & LED, $450 \mathrm{~nm}$ & $\mathrm{CDC}$ reaction & 24 & 98.5 & 5 & {$[63]$} \\
\hline CNPC & MOF-199 & $\mathrm{LED}, 450 \mathrm{~nm}$ & CDC reaction & 25 & 95 & 5 & [114] \\
\hline N-doped $\mathrm{TiO}_{2} @ \mathrm{~N}-\mathrm{C}$ & $\mathrm{NH}_{2}-\mathrm{MIL}-125$ & $\mathrm{LED}, 450 \mathrm{~nm}$ & $\begin{array}{l}\text { Oxidation cou- } \\
\text { pling of amine }\end{array}$ & 17 & 99 & 5 & [113] \\
\hline
\end{tabular}


with suitable structures and compositions. Our group have reported $\mathrm{N}$-doped $\mathrm{Cu}_{2} \mathrm{O} @ \mathrm{~N}-\mathrm{C}$ NP catalysts derived from a N-rich NTU-105, which share several favorable features for photocatalysis: (1) a porous $\mathrm{C}$ matrix substrate, which facilitated uniform distribution of the small $\mathrm{Cu}_{2} \mathrm{O}$ nanoparticles by stabilizing them and preventing their aggregation and (2) high conductivity, attributed to the $\mathrm{N}$-doped $\mathrm{Cu}_{2} \mathrm{O}$ and $\mathrm{C}$ substrate, which facilitated electron and hole transfer and separation [63]. The N-doped $\mathrm{Cu}_{2} \mathrm{O} @ \mathrm{~N}-\mathrm{C}$ NPs exhibited excellent performance in cross-dehydrogenative coupling (CDC) reactions, owning to the long-lived holes, whose existence was revealed by femtosecond transient absorption spectroscopy. By utilizing $\mathrm{NH}_{2}$-MIL-125 as a hard template, $\mathrm{N}$-doped $\mathrm{TiO}_{2} @ \mathrm{~N}-\mathrm{C}$ with butterfly structure (TNPC) was also fabricated as a highly efficient photocatalyst for visiblelight-induced amine oxidation [113]. Through an in-depth investigation with femtosecond transient absorption spectroscopy and DFT calculation, the number of actively longlived holes was found to be in the order $\mathrm{TiO}_{2}<\mathrm{N}$-doped $\mathrm{TiO}_{2}<\mathrm{TNPC}$, leading to significantly enhanced photocatalytic activity of TNPC.

Moreover, MOFs have been realized as the templates for the construction of multilevel structures of composites, which can improve the utilization efficiency of light through the multiple reflections, thereby enhancing the activity of photocatalytic organic reactions. Combined with the structural features of $\mathrm{N}$ doping and $\mathrm{C}$ compositing, $\mathrm{Cu}_{2} \mathrm{O}$ nanoparticles anchored on an $\mathrm{N}$-doped porous carbon yolk-shell cuboctahedral (CNPC) framework were fabricated with a benzimidazole-modified $\mathrm{Cu}$-btc MOF as the precursor, which possessed a multilevel structure at the same time (Fig. 10) [114]. Benefiting from the structural characteristics, the obtained CNPC nanoparticles, as a photocatalyst, provided several favorable features: prolonged lifetime of photogenerated electrons and holes, multiple reflection of light by the yolk-shell structure, and improved stability and dispersibility of $\mathrm{Cu}_{2} \mathrm{O}$ NPs, leading to excellent performance in $\mathrm{CDC}$ reactions under visible-light illumination.

In general, research on photocatalytic organic reactions over MOF-derived catalysts is still in its early stage, and more progress, such as development of more efficient photocatalytic systems from MOFs and broadening their applications in photoredox catalysis, needs to be made.

\section{Photocatalytic Pollutant Degradation}

Organic pollutants in water, as an overwhelming problem in environmental chemistry, have raised many concerns. Photodegradation of organic pollutants is considered an ideal strategy to solve the issue, which usually involves $\mathrm{O}_{2}$ as the oxidizing agent to degrade organic pollutants to $\mathrm{CO}_{2}$, water, and other inorganic species. Among the various photocatalytic systems, MOF-derived materials, such as porous metal oxides, metal sulfides, and their composites (mostly combined with carbon materials) can serve as highly potential photocatalysts due to the merits of high stability, excellent optical absorption/mass transfer, and improved electron-hole separation. In this part, we will summarize the progress in MOF-derived photocatalysts for the degradation of pollutants, which are mostly normal dye pollutants, such as methylene blue (MB), methyl orange (MO), and rhodamine B (RhB) (Fig. 11), and organic pollutants, for example, nitrobenzene. In Table 5, the performances of MOF-derived photocatalysts for pollutant degradation are presented.

\subsection{MOF-Derived Porous Metal Oxides}

As the most commonly used metal oxides in photocatalysis, $\mathrm{TiO}_{2}$ and $\mathrm{ZnO}$ show high activities for pollutant photodegradation. With proper MOFs as the precursors, $\mathrm{TiO}_{2}$ - and ZnO-based photocatalysts with highly improved performances could be obtained via a simple thermal treatment. For example, MIL-125, one of the earliest reported Ticontaining MOFs, is a good choice to fabricate $\mathrm{TiO}_{2}$-based photocatalysts, and according to reports, tunable products could be obtained by changing the calcining atmosphere. Pan's group achieved cake-like porous $\mathrm{TiO}_{2}$ particles with the mixed anatase/rutile $\left(\mathrm{A} / \mathrm{R} \mathrm{TiO}_{2}\right)$ phase via the pyrolysis of MIL-125 under air atmosphere; the as-prepared materials served as photocatalysts for nitrobenzene degradation [116]. Due to the reduced electron-hole pair recombination, the obtained $\mathrm{A} / \mathrm{R} \mathrm{TiO}_{2}$ showed better catalytic activity compared with pure rutile or anatase $\mathrm{TiO}_{2}$. Zhao and coworkers found that a series of $\mathrm{TiO}_{x} / \mathrm{C}$ composites could be obtained by the thermal treatment of MIL-125 under an Ar atmosphere; these composites exhibited high catalytic activities toward the photodegradation of MB under UV light [117]. In the series of $\mathrm{TiO}_{x} / \mathrm{C}$ composites, the product achieved at $1000{ }^{\circ} \mathrm{C}$ acted as the best photocatalyst due to its 

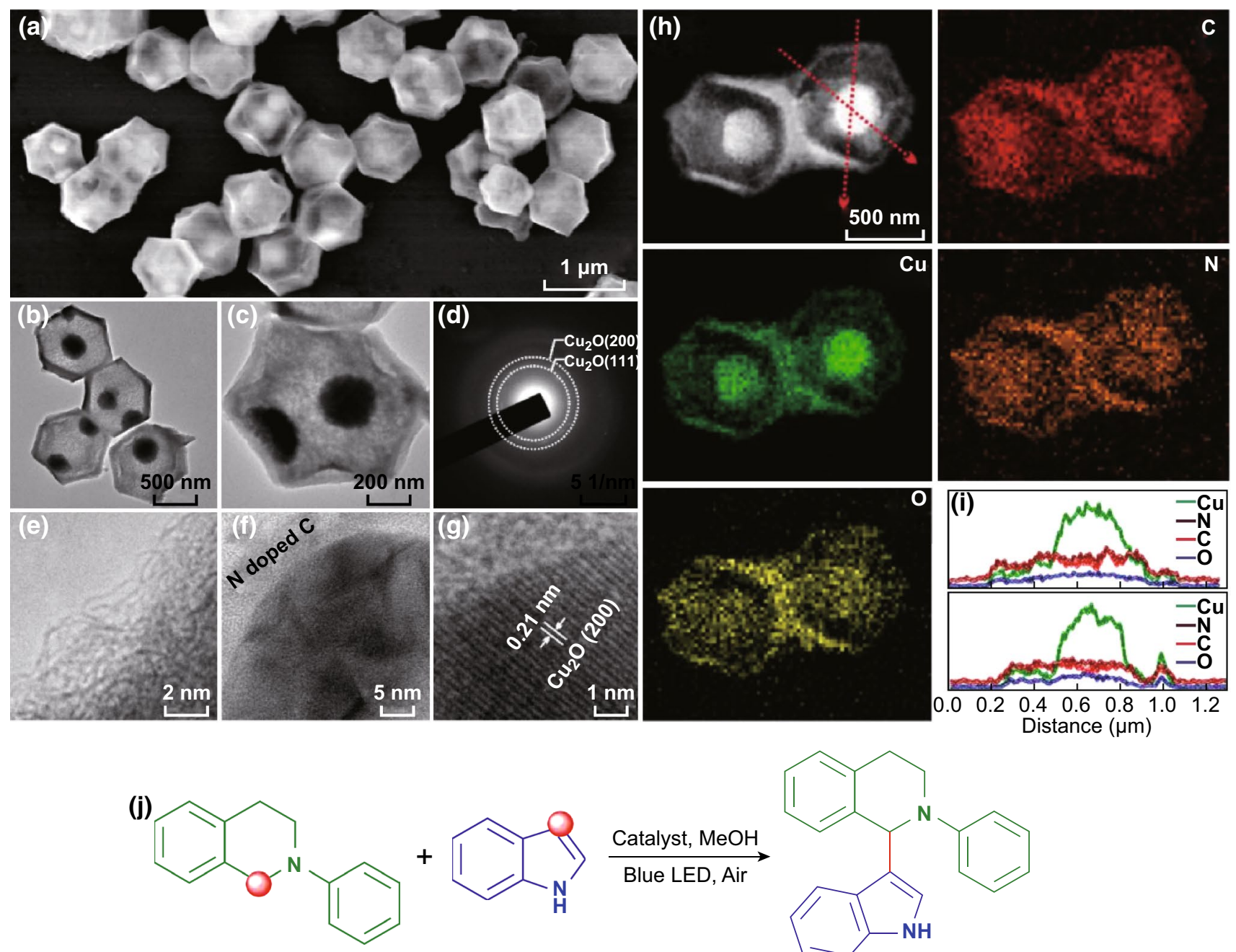<smiles></smiles>

$\underset{\text { Blue LED, Air }}{\stackrel{\text { Catalyst, } \mathrm{MeOH}}{\longrightarrow}}$
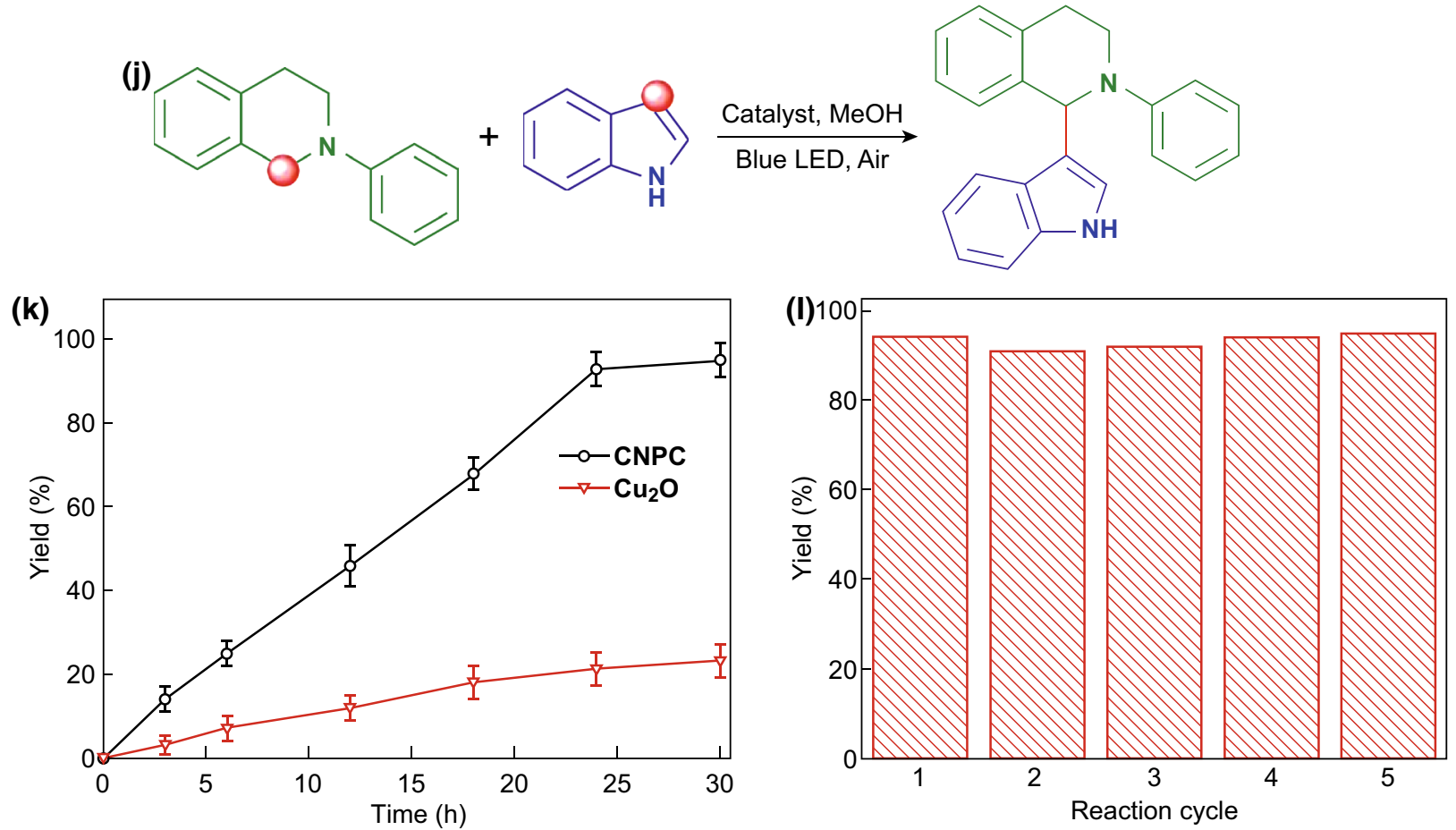

Fig. 10 Structure characterization of the core-shell cuboctahedron structure: a FESEM image, $\mathbf{b}$ and $\mathbf{c}$ TEM images, $\mathbf{d}$ SAED pattern, and e-g the corresponding HRTEM images. h STEM image of the core-shell cuboctahedron structure and the corresponding EDXS elemental mapping of $\mathrm{C}, \mathrm{Cu}, \mathrm{N}$, and $\mathrm{O}$ and $\mathbf{i}$ line profiles. $\mathbf{j}$ Photocatalytic equation and reaction conditions. $\mathbf{k}$ Product yield correlation with reaction time in the $\mathrm{CDC}$ reaction between indole and $\mathrm{N}$-aryl-tetrahydroisoquinoline catalyzed by different catalysts. I Cycling experiments using CNPC as the catalyst. Reprinted with the permission from Ref. [114] 
<smiles>CCN(CC)c1ccc2c(-c3cccc([N+](C)=O)c3)c3ccc(=[N+](C)CC)cc-3oc2c1</smiles>

high surface area, reduced $\mathrm{Ti}_{3} \mathrm{O}_{5}$ composition, and conductive carbon matrix. In addition, Zhao and coworkers also reported that the heterometallic MOF (ZTOF-1) containing $\mathrm{Zn}^{2+}$ and $\mathrm{Ti}^{4+}$ could be used as the precursor to fabricate $\mathrm{TiO}_{x}$-based catalysts, whereby $\mathrm{Zn}$ could be removed via vaporization at $1000{ }^{\circ} \mathrm{C}$, leading to the $\mathrm{TiO}_{x} / \mathrm{C}$ composite [118]. The obtained $\mathrm{TiO}_{x} / \mathrm{C}$ contained the extra pores formed in the process of vaporization of $\mathrm{Zn}$, and these were readily accessible to $\mathrm{MB}$, leading to a considerable increase in the

Fig. 11 Structures of the three normal dye pollutants

Table 5 Selected MOF derivatives that serve as photocatalysts for pollutant degradation

\begin{tabular}{|c|c|c|c|c|c|c|c|}
\hline Photocatalyst & MOF precursors & $E_{\mathrm{g}}(\mathrm{eV})$ & Target pollutant & Additive & $k\left(\min ^{-1}\right)$ & Illumination range & $\begin{array}{l}\text { Refer- } \\
\text { ences }\end{array}$ \\
\hline $\mathrm{ZnO} / \mathrm{RGO}$ & ZIF-8-RGO & 3.18 & MB & None & - & Visible light & [115] \\
\hline $\mathrm{Fe}_{3} \mathrm{O}_{4} @ \mathrm{C} / \mathrm{Cu}$ & $\mathrm{Fe}_{3} \mathrm{O}_{4} @ \mathrm{HKUST}-1$ & 1.75 & MB & $\mathrm{H}_{2} \mathrm{O}_{2}$ & - & Visible light & [131] \\
\hline $\mathrm{ZnS}$ & $\mathrm{Zn}-\mathrm{MOF}$ & - & MB & None & 0.0223 & Visible light & [132] \\
\hline $\mathrm{CdS}$ & $\mathrm{Cd}-\mathrm{MOF}$ & - & $\mathrm{MB}$ & None & 0.0238 & Visible light & [132] \\
\hline $\mathrm{C}, \mathrm{N}$-doped $\mathrm{ZnO}$ & $\mathrm{ZIF}-8$ & 2.98 & $\mathrm{MB}$ & None & 0.068 & UV-Vis light & [96] \\
\hline $\mathrm{In}_{2} \mathrm{O}_{3} / \mathrm{Co}_{3} \mathrm{O}_{4} @ \mathrm{PAL}$ composites & Co-In-MOFs-PAL composites & - & MB & None & - & UV-Vis light & [127] \\
\hline $\mathrm{ZnO} / 3 \mathrm{DGN}$ & ZIF-8-3DGN & - & MB & None & - & UV light & [121] \\
\hline $\mathrm{TiO}_{x} / \mathrm{C}$ & Zn-Ti heterometallic MOF & - & $\mathrm{MB}$ & None & 0.2224 & UV light & [118] \\
\hline $\mathrm{TiO}_{x} / \mathrm{C}$ & MIL-125 & - & $\mathrm{MB}$ & None & 0.0207 & UV light & [117] \\
\hline $\mathrm{MgO}$ nanorods & $\mathrm{Mg}-\mathrm{MOF}$ & - & $\mathrm{MB}$ & None & - & UV light & [123] \\
\hline Porous $\mathrm{ZnO}$ & ZIF-8 & - & MB & None & - & UV light & {$[61]$} \\
\hline $\mathrm{In}_{2} \mathrm{~S}_{3}$ & In-MOF & 2.07 & $\mathrm{MB}$ & None & - & UV light & [133] \\
\hline $\mathrm{ZnIn}_{2} \mathrm{~S}_{4}$ & $\mathrm{Zn}-\mathrm{MOF}$ and $\mathrm{In}-\mathrm{MOF}$ & 2.30 & MB & None & - & UV light & [133] \\
\hline $\mathrm{CdIn}_{2} \mathrm{~S}_{4}$ & $\mathrm{Cd}-\mathrm{MOF}$ and $\mathrm{In}-\mathrm{MOF}$ & 2.30 & MB & None & - & UV light & [133] \\
\hline porous $\mathrm{N}$-doped $\mathrm{Cu}_{2} \mathrm{O} / \mathrm{C}$ & $\mathrm{Cu}-\mathrm{MOF}$ & 2.2 & $\mathrm{MO}$ & None & - & Visible light & [128] \\
\hline $\begin{array}{l}\mathrm{ZnO} @ \mathrm{C}-\mathrm{N}-\mathrm{Co} \text { core-shell } \\
\text { nanostructure }\end{array}$ & Hollow Zn-Co-ZIF & - & MO & None & - & UV light & [119] \\
\hline ZnO@Silica & $\mathrm{ZIF}-8$ & - & MO & None & - & UV light & [115] \\
\hline C-doped $\mathrm{ZnO}$ & ZIF-8 & 2.93 & $\mathrm{RhB}$ & None & 0.0015 & Visible light & {$[62]$} \\
\hline $\mathrm{CoP} / \mathrm{Fe}_{2} \mathrm{P} @ \mathrm{mC}$ & $\mathrm{Co}-\mathrm{Fe}-\mathrm{MOF}$ & 2.11 & $\mathrm{RhB}$ & None & - & Visible light & [138] \\
\hline $\mathrm{CuO}$ nanofibers & $\mathrm{Cu}-\mathrm{MOF}$ & - & $\mathrm{RhB}$ & $\mathrm{H}_{2} \mathrm{O}_{2}$ & 0.01712 & Visible light & [124] \\
\hline $\mathrm{Zn}_{0.95} \mathrm{Co}_{0.05}-\mathrm{ZIF} @ \mathrm{Zn}_{0.95} \mathrm{Co}_{0.05} \mathrm{O}$ & $\mathrm{Zn}_{0.95} \mathrm{Co}_{0.05}-\mathrm{ZIF}$ & - & $\mathrm{RhB}$ & None & 0.41 & Visible light & [134] \\
\hline $\mathrm{Au} / \mathrm{ZnO}$ & GSH-Au NCs-ZIF-8 & 3.17 & $\mathrm{RhB}$ & None & - & Visible light & [67] \\
\hline Porous N-doped $\mathrm{ZnO}$ & Urea and ZIF-8 mixture & - & $\mathrm{RhB}$ & None & 0.0049 & Visible light & {$[120]$} \\
\hline Porous $\mathrm{ZnO}$ & MOF-5 & - & RhB & None & 0.0053 & UV light & [139] \\
\hline ZIF-8@ $\mathrm{Zn}_{0.95} \mathrm{Ni}_{0.05} \mathrm{O}$ & ZIF-8-Ni ${ }^{2+}$ & - & $\mathrm{RhB}$ & None & 0.175 & UV light & [136] \\
\hline$\gamma-\mathrm{Fe}_{2} \mathrm{O}_{3} / \mathrm{C}$ & MIL-53(Fe) & - & MG & $\mathrm{H}_{2} \mathrm{O}_{2}$ & - & Solar light & [129] \\
\hline $\mathrm{CdS} / \mathrm{MPC}$ & ZIF-8 & - & Cephalexin & None & 0.024 & UV-Vis light & [137] \\
\hline ZIF-NC/g- $\mathrm{C}_{3} \mathrm{~N}_{4}$ & ZIF-8 & - & BPA & $\mathrm{HSO}_{5}^{-}$ & 0.05134 & Visible light & {$[135]$} \\
\hline $\mathrm{A} / \mathrm{R} \mathrm{TiO}_{2}$ & MIL-125 & 3.07 & Nitrobenzene & None & - & UV light & [116] \\
\hline \multirow[t]{4}{*}{$\mathrm{GdCoO}_{3}$} & $\mathrm{Gd}-\mathrm{Co}-\mathrm{MOF}$ & - & OG & None & - & UV light & [126] \\
\hline & & & RBBR & None & - & UV light & \\
\hline & & & $\mathrm{RhB}$ & None & - & UV light & \\
\hline & & & RBL & None & - & UV light & \\
\hline
\end{tabular}



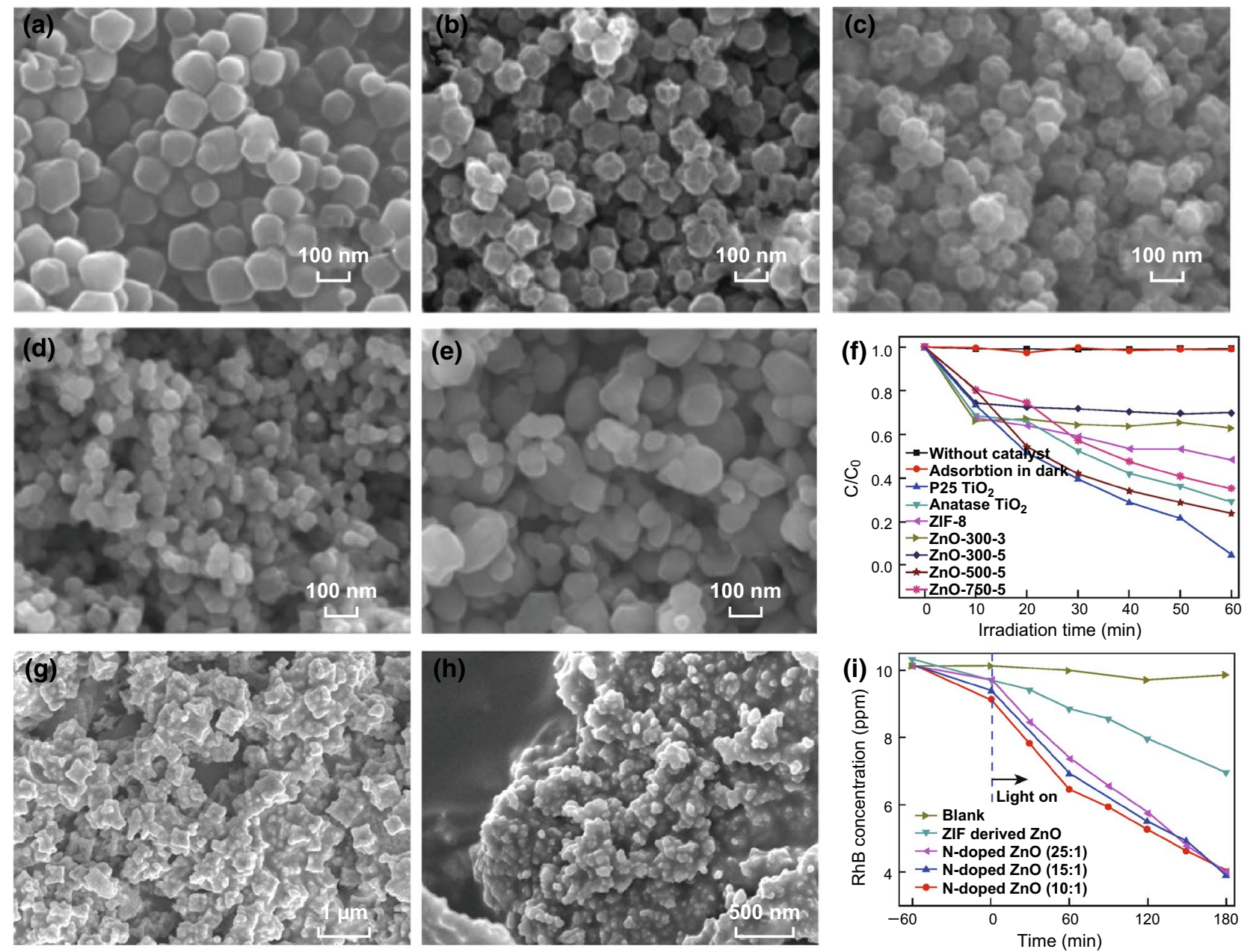

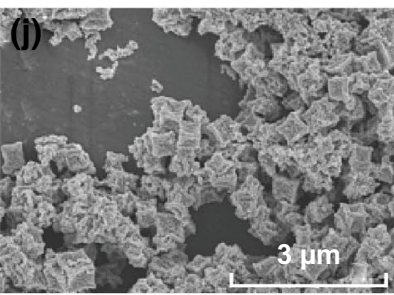

(I)

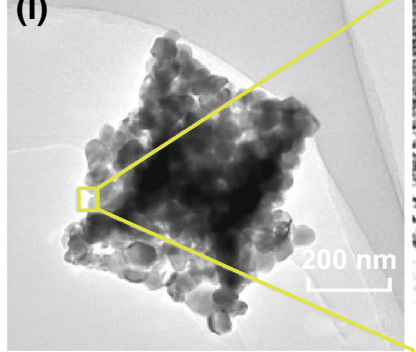

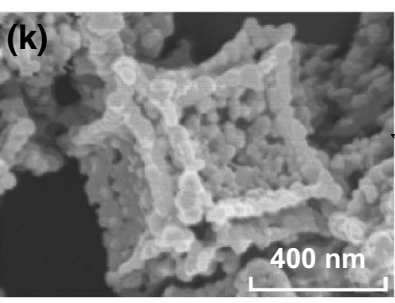

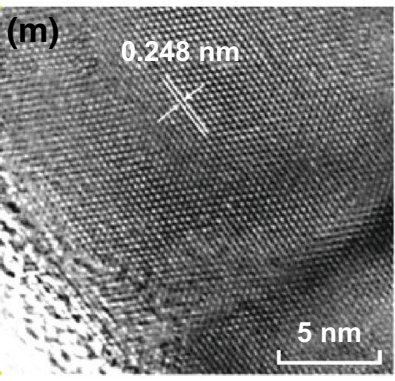

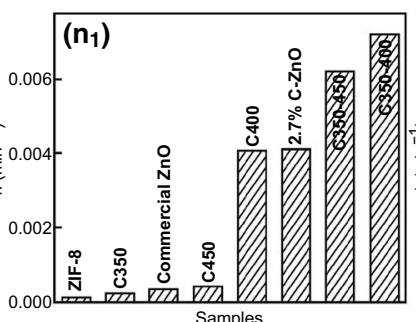
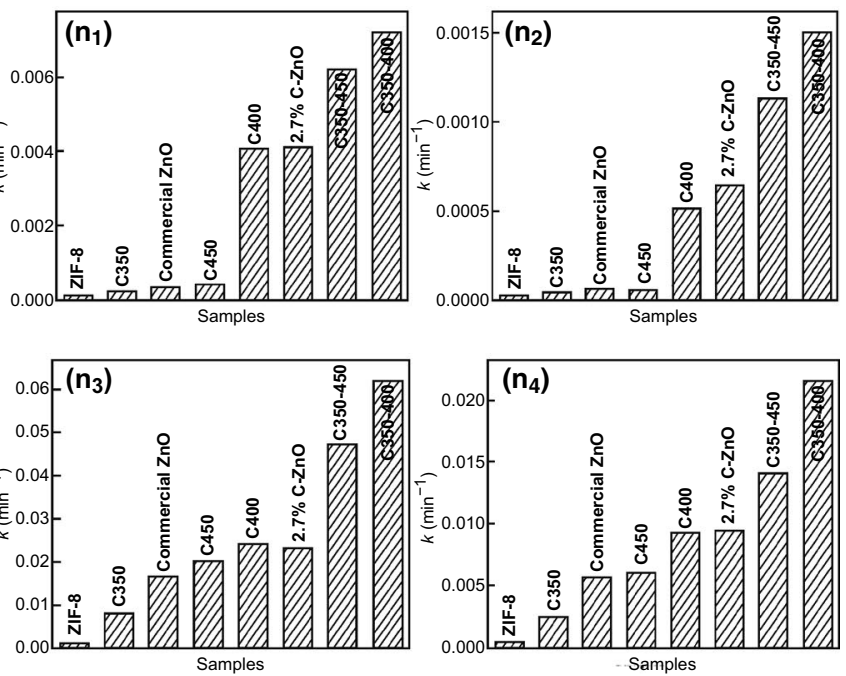

Fig. 12 SEM images of a ZIF-8, b ZnO-300-3, c ZnO-300-5, d ZnO-500-5, and e ZnO-750-5. f Photodegradation of MB over different catalysts. SEM images of $\mathbf{g} \mathrm{ZIF}-8$-derived pure $\mathrm{ZnO}$ and $\mathbf{h} \mathrm{N}$-doped $\mathrm{ZnO}$. i Photodegradation of $\mathrm{RhB}$ by blank (absence of photocatalyst), pure $\mathrm{ZnO}$, and N-doped ZnO with different ratios of urea and ZIF-8 as the precursors. SEM (j, k) and TEM (l, m) images of C350-400. j The calculated reaction rates $\mathbf{k}$ for $\mathrm{RhB}\left(n_{1}\right)$ and phenol $\left(n_{2}\right)$ photodegradation under visible light $(>420 \mathrm{~nm}), k$ for $\operatorname{RhB}\left(n_{3}\right)$ and phenol $\left(n_{4}\right)$ photodegradation under UV-Vis light (Xenon light) a-f are reprinted with permission from Ref. [61]. $\mathbf{g}-\mathbf{i}$ are reprinted with permission from Ref. [120]. j-n are reprinted with permission from Ref. [62] 
photocatalytic activity compared with that of the pyrolytic products obtained below $1000{ }^{\circ} \mathrm{C}$.

ZIF-8 or its hybrids have been commonly utilized as the precursors to fabricate $\mathrm{ZnO}$-based materials as catalysts for pollutant photodegradation $[67,115,119]$. In the past few years, various $\mathrm{ZnO}$-based photocatalytic systems, including porous $\mathrm{ZnO}$, porous $\mathrm{C}$ - or/and $\mathrm{N}$-doped $\mathrm{ZnO}, \mathrm{ZnO} /$ carbon materials composites, and other ZnO-based composites, were fabricated (Fig. 12). With pure ZIF-8 as the template and precursor, which contains ligands with nitrogen, i.e., 2-methylimidazole, the resulting products could be tuned as porous $\mathrm{ZnO}$, porous $\mathrm{C}$-doped $\mathrm{ZnO}$, and porous $\mathrm{C}, \mathrm{N}$-doped $\mathrm{ZnO}$ by changing the calcination conditions, including calcination atmosphere, calcination step, and calcination temperature $[61,62,96]$, while, with the mixture of ZIF-8 and urea as the precursors, N-doped $\mathrm{ZnO}$ could be obtained [120]. A photocatalytic investigation on these catalysts proved that they all performed well in dye degradation; particularly, porous $\mathrm{C}$-doped $\mathrm{ZnO}$ reported by Zhang and coworkers and porous $\mathrm{N}$-doped $\mathrm{ZnO}$ reported by Yao's group exhibited visible-light photodegradation of $\mathrm{RhB}$ due to the narrower band gap of $\mathrm{C}$ - and $\mathrm{N}$-doped $\mathrm{ZnO}$ $[62,120]$. When combined with carbon materials such as three-dimensional graphene networks (3DGN), ZIF-8-based hybrids could be transformed to the corresponding $\mathrm{ZnO}$ based hybrids [121]. Zhang's group developed a method to synthesize the $\mathrm{ZnO} / 3 \mathrm{DGN}$ composite via a two-step annealing process with ZIF-8/3DGN as the precursor, whereby ZIF-8/3DGN was fabricated by the direct synthesis of ZIF-8 on 3DGN. The obtained ZnO/3DGN exhibited high activity in MB photodegradation as well as durability. Zhu and coworkers incorporated RGO to ZIF-8-derived $\mathrm{ZnO}$ via the microwave-assisted method to fabricate $\mathrm{ZnO} / \mathrm{RGO}$ hybrids [122]. Attributed to the synergistic effect of enhanced light absorption and suppression of charge carrier recombination resulting from the interaction between $\mathrm{ZnO}$ and $\mathrm{RGO}$, the $\mathrm{ZnO} / \mathrm{RGO}$ composites were able to show higher activity for the visible-light degradation of $\mathrm{MB}$ than pure $\mathrm{ZnO}$. In the series of composites with different amounts of RGO, the as-prepared composite with $1.5 \mathrm{wt} \%$ of RGO showed an optimal photocatalytic performance.

In addition to $\mathrm{TiO}_{2}$ and $\mathrm{ZnO}$, other metal oxide-based photocatalysts for the pollutant degradation have also been derived from the corresponding MOF materials [123-125]. In 2007, Madras and Natarajan et al. reported the photodegradation of four organic pollutants, including $\mathrm{RhB}$,
Rhodamine Blue (RBL), Orange G (OG), and Remazol Brilliant Blue R (RBBR), with a bimetallic Gd/Co-MOFderived nanosized $\mathrm{GdCoO}_{3}$ as the catalyst [126]. At different calcination temperatures, $\mathrm{GdCoO}_{3}$ with different particle sizes could be obtained. Compared with P25, the as-synthesized $\sim 3 \mathrm{~nm} \mathrm{GdCoO}_{3}$ particles showed higher rates of degradation rates for the four pollutants. Wang's group has fabricated $\mathrm{In}_{2} \mathrm{O}_{3} / \mathrm{Co}_{3} \mathrm{O}_{4}$-palygorskite (PAL) composite photocatalysts for the degradation of $\mathrm{MB}$ and tetracycline (TC) from a Co/In-MOF/PAL hybrid [127]. In the presence of PAL, the photocatalytic activities were improved due to their higher adsorption of the substrates and the electrostatic interactions between photogenerated charge carriers and negatively charged PAL. Two-dimensional (2D) porous $\mathrm{N}$-doped $\mathrm{Cu}_{2} \mathrm{O} / \mathrm{C}$ composites derived from square-shaped $\mathrm{Cu}-\mathrm{MOF}$ nanoplatelets as a photocatalyst for MO degradation were reported by $\mathrm{Ma}$ and coworkers [128]. The high surface area of the annealed $\mathrm{Cu}_{2} \mathrm{O} / \mathrm{C}$ nanoplatelets led to a high degradation rate of $2.5 \mathrm{mg} \mathrm{min}^{-1} \mathrm{~g}^{-1}$ for MO pollution under visible light. Moreover, magnetic photocatalysts, such as $\gamma-\mathrm{Fe}_{2} \mathrm{O}_{3} / \mathrm{C}, \mathrm{Co} /$ graphene materials, $\mathrm{Fe}_{3} \mathrm{O}_{4} @ \mathrm{C} / \mathrm{Cu}$, and $\mathrm{Fe}_{3} \mathrm{O}_{4} @ \mathrm{CuO}$, for the degradation of pollutants with the advantage of easy separability were fabricated for the degradation of pollutants from the corresponding MOFs or MOF-based composites; these photocatalysts acted well in terms of both activity and reusability [129-131].

\subsection{MOF-Derived Porous Metal Sulfides}

Various metal sulfides with tunable structures and morphologies have been fabricated via the sulfurization process or thermal treatment of MOFs. For instance, $\mathrm{Li}$ and coworkers developed a series of $\mathrm{M}_{x} \mathrm{~S}_{\mathrm{y}} @ \mathrm{C}(\mathrm{M}=\mathrm{Co}, \mathrm{Zn}, \mathrm{Cd}, \mathrm{Ni}$, and $\mathrm{Cu})$ through one-pot sulfurization of five MOFs with the identical formula of $[\mathrm{M}(\mathrm{pa})(\mathrm{bib})]_{\infty}$ [132]. Among them, pure $\mathrm{ZnS}$ and $\mathrm{CdS}$ were subsequently obtained by the combustion of ZnS@C and CdS@C (to remove carbon) and utilized as moderately active photocatalysts for degradation of MB under visible-light illumination. Batabyal and coworkers developed a one-pot method, i.e., thermolysis of single- or dual-source coordination polymer precursors in the presence of different surfactants, to synthesize nanocrystals of $\operatorname{In}_{2} \mathrm{~S}_{3}, \mathrm{ZnIn}_{2} \mathrm{~S}_{4}$, and $\mathrm{CdIn}_{2} \mathrm{~S}_{4}$ [133]. The synthesized $\operatorname{In}_{2} \mathrm{~S}_{3}$ nanocrystals showed efficient photocatalytic degradation of MB under UV light 
irradiation, and the photocatalytic activities of the ternary chalcogenides of $\operatorname{In}_{2} \mathrm{~S}_{3}$ were considerably enhanced.

In addition to MOF-derived metal oxides, metal sulfides, and their composites, some other kinds of MOF-derived materials have been reported as highly efficient photocatalysts for the degradation of organic pollutants, such as MOFderived metal phosphide composites, MOF-derived carbonmodified g- $\mathrm{C}_{3} \mathrm{~N}_{4}$, semi-transformed MOFs hybrids, and so on [134-137]. Although there are numerous papers focused on the photodegradation of organic pollutants with porous nanostructures derived from MOFs as photocatalysts, the gap between laboratory research and industrial application is still huge due to the following issues: (1) most of the MOF-derived photocatalysts show limited absorption of visible light and (2) the degradation mechanism is not thoroughly explored, and the degradation products are not clear. Therefore, more in-depth research on MOF-derived photocatalysts for the degradation of organic pollutants should be carried out.

\section{Summary and Outlook}

In this review, we have discussed the improvements in MOFderived porous structures serving as photocatalysts for various energy-/environment-related reactions, including water splitting, pollutant degradation, $\mathrm{CO}_{2}$ reduction, and organic reactions, achieved in the last few years. Owing to the beneficial structural features, such as versatility in components and well-defined pore structures, MOFs have been considered as the ideal precursors of porous semiconductor photocatalysts, including porous metal oxides and porous metal sulfides, and their heterostructures. The derived porous photocatalysts exhibit enhanced performances toward various reactions due to their high accessible surface areas and rich pore structures. Moreover, porous heterostructures or solid solution photocatalysts can be rationally designed from multimetallic MOFs as the precursors. With tuned band gap, increased active sites, and increased efficiency of photogenerated charge carrier separation and migration, the photocatalytic activities of MOF-derived porous heterostructures and solid solutions have been further enhanced.

Despite the great progress achieved in the field of MOFderived photocatalyst development, there are some pending issues that need to be solved. Transformation processes always involve high-temperature reactions and lack precise control over the pore structure and active sites, which, however, will have great influence on the photocatalytic performances. Therefore, more efforts should be devoted to the controlled synthesis of MOF-derived materials with desired pore structures as well as the active sites, which also call forth in situ techniques to track the transformation process of MOFs. Moreover, MOF-derived semiconductor photocatalysts suffer from low solar-to-chemical-energy conversion efficiency because only a few photocatalytic systems can mainly utilize the energy of the UV region, which is only $5 \%$ of the solar spectrum. The development of visible or near-infrared (NIR) light-driven photocatalytic systems with fast kinetics is still in active demand. Fabrication of composites with heterojunctions has shown its superiority in promoting charge separation, yet the intrinsic mechanism is far from well understood. An in-depth investigation should be carried out; the combination of experimental investigation and the corresponding theoretical calculation seems to be an effective method.

Finally, the other issues and their possible recommendations are listed below toward the specific reactions. For photocatalytic water splitting, the currently developed photocatalysts derived from MOFs are aimed at only one isolated half-reaction, and sacrificial reagents are added to replace the other half-reaction. Yet the goal to produce hydrogen at a cost and scale that are comparable with fossil fuels should be realized by rational design of highly efficient water-splitting photocatalysts that can split pure water into stoichiometric amounts of $\mathrm{H}_{2}$ and $\mathrm{O}_{2}$, driven by sunlight without using any sacrificial reagents. Thus, MOFs-derived photocatalysts for overall water splitting are highly desired. For photocatalytic $\mathrm{CO}_{2}$ reduction, the study is in its infancy, and the lower efficiency and selectivity of MOF-derived photocatalysts make it difficult to meet the demands of industrial applications, and therefore, further efforts are needed to make a breakthrough in the fabrication of photocatalysts. From the viewpoints of design principles, the increased adsorption of $\mathrm{CO}_{2}$ can improve the reduction efficiency of $\mathrm{CO}_{2}$. The exposure of special surface sites that can decrease the energy barrier of the reduction process or the enrichment of $\mathrm{CO}_{2}$ molecules around the active sites can help to improve the photocatalytic performance. For photocatalytic organic redox reaction, hole scavengers or electron scavengers are usually used, and designing appropriate tandem reactions can help to avoid their use. With regard to photocatalytic pollutant degradation, research is mainly focused on the degradation of the dye pollutants and some organic pollutants 
by photogenerated reactive transient species of $\mathrm{O}_{2}$. Owing to the non-selective property of the reactive species, the conclusion about the activity of photocatalysts is not accurate. In-depth research on MOF-derived photocatalysts with thoroughly explored degradation mechanism and clear degradation products should be carried out.

In this review, we give a comprehensive survey of MOFderived porous semiconductor structures as very promising photocatalysts toward various reactions. Given the beneficial features of porous structure and well-defined heterostructures, we believe that MOF-derived porous semiconductor structures will present a bright future toward photocatalysis.

Acknowledgements This work was supported by the National Natural Science Foundation of China (Grant Nos. 21671085, 21701063), the Jiangsu Province Science Foundation for Youths (BK20150237), the Natural Science Foundation of Jiangsu Province (BK20161160), the Project Funded by the Priority Academic Program Development of Jiangsu Higher Education Institutions.

Open Access This article is distributed under the terms of the Creative Commons Attribution 4.0 International License (http:// creativecommons.org/licenses/by/4.0/), which permits unrestricted use, distribution, and reproduction in any medium, provided you give appropriate credit to the original author(s) and the source, provide a link to the Creative Commons license, and indicate if changes were made.

\section{References}

1. M.R. Hoffmann, S.T. Martin, W.Y. Choi, D.W. Bahnemann, Environmental applications of semiconductor photocatalysis. Chem. Rev. 95(1), 69-96 (1995). https://doi.org/10.1021/ cr00033a004

2. M.A. Fox, M.T. Dulay, Heterogeneous photocatalysis. Chem. Rev. 93(1), 341-357 (1993). https://doi.org/10.1021/cr000 $17 \mathrm{a} 016$

3. A. Mills, S. LeHunte, An overview of semiconductor photocatalysis. J. Photochem. Photobiol., A 108(1), 1-35 (1997). https://doi.org/10.1016/S1010-6030(97)00118-4

4. R. Asahi, T. Morikawa, T. Ohwaki, K. Aoki, Y. Taga, Visible-light photocatalysis in nitrogen-doped titanium oxides. Science 293(5528), 269-271 (2001). https://doi.org/10.1126/ science. 1061051

5. S. Sakthivel, H. Kisch, Daylight photocatalysis by carbonmodified titanium dioxide. Angew. Chem. Int. Ed. 42(40), 4908-4911 (2003). https://doi.org/10.1002/anie.200351577

6. H. Tong, S. Ouyang, Y. Bi, N. Umezawa, M. Oshikiri, J. Ye, Nano-photocatalytic materials: possibilities and challenges. Adv. Mater. 24(2), 229-251 (2012). https://doi.org/10.1002/ adma.201102752
7. S. Linic, P. Christopher, D.B. Ingram, Plasmonic-metal nanostructures for efficient conversion of solar to chemical energy. Nat. Mater. 10(12), 911-921 (2011). https://doi.org/10.1038/ nmat3151

8. M. Ni, M.K.H. Leung, D.Y.C. Leung, K. Sumathy, A review and recent developments in photocatalytic water-splitting using $\mathrm{TiO}_{2}$ for hydrogen production. Renew. Sustain. Energy Rev. 11(3), 401-425 (2007). https://doi.org/10.1016/j. rser.2005.01.009

9. W. Tu, Y. Zhou, Z. Zou, Photocatalytic conversion of $\mathrm{CO}_{2}$ into renewable hydrocarbon fuels: state-of-the-art accomplishment, challenges, and prospects. Adv. Mater. 26(27), 4607-4626 (2014). https://doi.org/10.1002/adma.201400087

10. R. Marschall, Semiconductor composites: strategies for enhancing charge carrier separation to improve photocatalytic activity. Adv. Funct. Mater. 24(17), 2421-2440 (2014). https ://doi.org/10.1002/adfm.201303214

11. K. Maeda, K. Domen, Photocatalytic water splitting: recent progress and future challenges. J. Phys. Chem. Lett. 1(18), 2655-2661 (2010). https://doi.org/10.1021/jz1007966

12. C.-F. Du, Q. Liang, R. Dangol, J. Zhao, H. Ren, S. Madhavi, Q. Yan, Layered trichalcogenidophosphate: a new catalyst family for water splitting. Nano Micro Lett. 10(4), 67 (2018). https://doi.org/10.1007/s40820-018-0220-6

13. T. Su, Q. Shao, Z. Qin, Z. Guo, Z. Wu, Role of interfaces in two-dimensional photocatalyst for water splitting. ACS Catal. 8(3), 2253-2276 (2018). https://doi.org/10.1021/acsca tal.7b03437

14. C.B. Ong, L.Y. Ng, A.W. Mohammad, A review of $\mathrm{ZnO}$ nanoparticles as solar photocatalysts: synthesis, mechanisms and applications. Renew. Sustain. Energy Rev. 81, 536-551 (2018). https://doi.org/10.1016/j.rser.2017.08.020

15. S.G. Kumar, K.S.R.K. Rao, Zinc oxide based photocatalysis: tailoring surface-bulk structure and related interfacial charge carrier dynamics for better environmental applications. RSC Adv. 5(5), 3306-3351 (2015). https://doi.org/10.1039/C4RA13299H

16. K.M. Lee, C.W. Lai, K.S. Ngai, J.C. Juan, Recent developments of zinc oxide based photocatalyst in water treatment technology: a review. Water Res. 88, 428-448 (2016). https ://doi.org/10.1016/j.watres.2015.09.045

17. E. Rahmanian, R. Malekfar, M. Pumera, Nanohybrids of twodimensional transition-metal dichalcogenides and titanium dioxide for photocatalytic applications. Chem. Eur. J. 24(1), 18-31 (2018). https://doi.org/10.1002/chem.201703434

18. B. Chen, Y. Meng, J. Sha, C. Zhong, W. Hua, N. Zhao, Preparation of $\mathrm{MoS}_{2} / \mathrm{TiO}_{2}$ based nanocomposites for photocatalysis and rechargeable batteries: progress, challenges, and perspective. Nanoscale 10(1), 34-68 (2018). https://doi.org/10.1039/ C7NR07366F

19. X. Chen, L. Liu, P.Y. Yu, S.S. Mao, Increasing solar absorption for photocatalysis with black hydrogenated titanium dioxide nanocrystals. Science 331(6018), 746-750 (2011). https://doi.org/10.1126/science.1200448

20. S.U.M. Khan, M. Al-Shahry, W.B. Ingler, Efficient photochemical water splitting by a chemically modified 
n- $\mathrm{TiO}_{2}$. Science 297(5590), 2243-2245 (2002). https://doi. org/10.1126/science. 1075035

21. M. Ge, Q. Li, C. Cao, J. Huang, S. Li et al., One-dimensional $\mathrm{TiO}_{2}$ nanotube photocatalysts for solar water splitting. Adv. Sci. (2017). https://doi.org/10.1002/advs.201600152

22. Y. Song, N. Li, D. Chen, Q. Xu, H. Li, J. He, J. Lu, 3D ordered mop inverse opals deposited with CdS quantum dots for enhanced visible light photocatalytic activity. Appl. Catal. B Environ. 238, 255-262 (2018). https://doi.org/10.1016/j. apcatb.2018.07.010

23. Q. Li, B. Guo, J. Yu, J. Ran, B. Zhang, H. Yan, J.R. Gong, Highly efficient visible-light-driven photocatalytic hydrogen production of CdS-cluster-decorated graphene nanosheets. J. Am. Chem. Soc. 133(28), 10878-10884 (2011). https://doi. org/10.1021/ja2025454

24. X. Zong, H. Yan, G. Wu, G. Ma, F. Wen, L. Wang, C. Li, Enhancement of photocatalytic $\mathrm{H}_{2}$ evolution on $\mathrm{CdS}$ by loading $\mathrm{MoS}_{2}$ as cocatalyst under visible light irradiation. J. Am. Chem. Soc. 130(23), 7176-7177 (2008). https://doi. org/10.1021/ja8007825

25. L. Jiang, X. Yuan, Y. Pan, J. Liang, G. Zeng, Z. Wu, H. Wang, Doping of graphitic carbon nitride for photocatalysis: a review. Appl. Catal. B Environ. 217, 388-406 (2017). https ://doi.org/10.1016/j.apcatb.2017.06.003

26. G. Zhang, Z.-A. Lan, X. Wang, Surface engineering of graphitic carbon nitride polymers with cocatalysts for photocatalytic overall water splitting. Chem. Sci. 8(8), 5261-5274 (2017). https://doi.org/10.1039/C7SC01747B

27. J. Fei, J. Li, Controlled preparation of porous $\mathrm{TiO}_{2}-\mathrm{Ag}$ nanostructures through supramolecular assembly for plasmonenhanced photocatalysis. Adv. Mater. 27(2), 314-319 (2015). https://doi.org/10.1002/adma.201404007

28. M.H. Sun, S.Z. Huang, L.H. Chen, Y. Li, X.Y. Yang, Z.Y. Yuan, B.L. Su, Applications of hierarchically structured porous materials from energy storage and conversion, catalysis, photocatalysis, adsorption, separation, and sensing to biomedicine. Chem. Soc. Rev. 45(12), 3479-3563 (2016). https://doi.org/10.1039/C6CS00135A

29. B. Lu, X. Li, T. Wang, E. Xie, Z. Xu, $\mathrm{WO}_{3}$ nanoparticles decorated on both sidewalls of highly porous $\mathrm{TiO}_{2}$ nanotubes to improve UV and visible-light photocatalysis. J. Mater. Chem. A 1(12), 3900-3906 (2013). https://doi.org/10.1039/ c3ta01444d

30. S. Wang, X. Wang, Multifunctional metal-organic frameworks for photocatalysis. Small 11(26), 3097-3112 (2015). https://doi.org/10.1002/smll.201500084

31. B. Qiu, M. Xing, J. Zhang, Mesoporous $\mathrm{TiO}_{2}$ nanocrystals grown in situ on graphene aerogels for high photocatalysis and lithium-ion batteries. J. Am. Chem. Soc. 136(16), 58525855 (2014). https://doi.org/10.1021/ja500873u

32. J. Yu, Y. Su, B. Cheng, Template-free fabrication and enhanced photocatalytic activity of hierarchical macro-/ mesoporous titania. Adv. Funct. Mater. 17(12), 1984-1990 (2007). https://doi.org/10.1002/adfm.200600933

33. Q. Liang, Z. Li, X. Yu, Z.H. Huang, F. Kang, Q.H. Yang, Macroscopic 3D porous graphitic carbon nitride monolith for enhanced photocatalytic hydrogen evolution. Adv. Mater. 27(31), 4634-4639 (2015). https://doi.org/10.1002/ adma.201502057

34. C. Chen, W. Cai, M. Long, B. Zhou, Y. Wu, D. Wu, Y. Feng, Synthesis of visible-light responsive graphene oxide/ $\mathrm{TiO}_{2}$ composites with $\mathrm{p} / \mathrm{n}$ heterojunction. ACS Nano 4(11), 6425-6432 (2010). https://doi.org/10.1021/nn102130m

35. H. Wang, L. Zhang, Z. Chen, J. Hu, S. Li, Z. Wang, J. Liu, X. Wang, Semiconductor heterojunction photocatalysts: design, construction, and photocatalytic performances. Chem. Soc. Rev. 43(15), 5234-5244 (2014). https://doi.org/10.1039/ C4CS00126E

36. Y. Bessekhouad, D. Robert, J.V. Weber, Photocatalytic activity of $\mathrm{Cu}_{2} \mathrm{O} / \mathrm{TiO}_{2}, \mathrm{Bi}_{2} \mathrm{O}_{3} / \mathrm{TiO}_{2}$ and $\mathrm{ZnMn}_{2} \mathrm{O}_{4} / \mathrm{TiO}_{2}$ heterojunctions. Catal. Today 101(3-4), 315-321 (2005). https:// doi.org/10.1016/j.cattod.2005.03.038

37. F. Dong, Z. Zhao, T. Xiong, Z. Ni, W. Zhang, Y. Sun, W.K. Ho, In situ construction of g- $\mathrm{C}_{3} \mathrm{~N}_{4} / \mathrm{g}-\mathrm{C}_{3} \mathrm{~N}_{4}$ metal-free heterojunction for enhanced visible-light photocatalysis. ACS Appl. Mater. Interfaces. 5(21), 11392-11401 (2013). https:// doi.org/10.1021/am403653a

38. D. Lin, H. Wu, R. Zhang, W. Pan, Enhanced photocatalysis of electrospun $\mathrm{Ag}-\mathrm{ZnO}$ heterostructured nanofibers. Chem. Mater. 21(15), 3479-3484 (2009). https://doi.org/10.1021/ cm900225p

39. J. Low, J. Yu, M. Jaroniec, S. Wageh, A.A. Al-Ghamdi, Heterojunction photocatalysts. Adv. Mater. (2017). https://doi. org/10.1002/adma.201601694

40. Z. Zhang, C. Shao, X. Li, C. Wang, M. Zhang, Y. Liu, Electrospun nanofibers of p-type $\mathrm{NiO} / \mathrm{n}$-type $\mathrm{ZnO}$ heterojunctions with enhanced photocatalytic activity. ACS Appl. Mater. Interfaces. 2(10), 2915-2923 (2010). https://doi.org/10.1021/ am $100618 \mathrm{~h}$

41. D. Sarkar, C.K. Ghosh, S. Mukherjee, K.K. Chattopadhyay, Three dimensional $\mathrm{Ag}_{2} \mathrm{O} / \mathrm{TiO}_{2}$ type-II ( $\mathrm{p}-\mathrm{n}$ ) nanoheterojunctions for superior photocatalytic activity. ACS Appl. Mater. Interfaces. 5(2), 331-337 (2013). https://doi.org/10.1021/ am302136y

42. Y. Cho, S. Kim, B. Park, C.L. Lee, J.K. Kim et al., Multiple heterojunction in single titanium dioxide nanoparticles for novel metal-free photocatalysis. Nano Lett. 18(7), 4257-4262 (2018). https://doi.org/10.1021/acs.nanolett.8b01245

43. A. Schneemann, V. Bon, I. Schwedler, I. Senkovska, S. Kaskel, R.A. Fischer, Flexible metal-organic frameworks. Chem. Soc. Rev. 43(16), 6062-6096 (2014). https://doi. org/10.1039/C4CS00101J

44. M.R. Lohe, K. Gedrich, T. Freudenberg, E. Kockrick, T. Dellmann, S. Kaskel, Heating and separation using nanomagnetfunctionalized metal-organic frameworks. Chem. Commun. 47(11), 3075-3077 (2011). https://doi.org/10.1039/c0cc0 $5278 \mathrm{~g}$

45. X. Zhu, H. Zheng, X. Wei, Z. Lin, L. Guo, B. Qiu, G. Chen, Metal-organic framework (MOF): a novel sensing platform for biomolecules. Chem. Commun. 49(13), 1276-1278 (2013). https://doi.org/10.1039/c2cc36661d 
46. S. Li, F. Huo, Metal-organic framework composites: from fundamentals to applications. Nanoscale 7(17), 7482-7501 (2015). https://doi.org/10.1039/C5NR00518C

47. L.E. Kreno, K. Leong, O.K. Farha, M. Allendorf, R.P. Van Duyne, J.T. Hupp, Metal-organic framework materials as chemical sensors. Chem. Rev. 112(2), 1105-1125 (2012). https://doi.org/10.1021/cr200324t

48. H. Furukawa, N. Ko, Y.B. Go, N. Aratani, S.B. Choi et al., Ultrahigh porosity in metal-organic frameworks. Science 329(5990), 424-428 (2010). https://doi.org/10.1126/scien ce. 1192160

49. G. Maurin, C. Serre, A. Cooper, G. Férey, The new age of MOFs and of their porous-related solids. Chem. Soc. Rev. 46(11), 3104-3107 (2017). https://doi.org/10.1039/C7CS9 0049J

50. Y. Li, H. Xu, S. Ouyang, J. Ye, Metal-organic frameworks for photocatalysis. Phys. Chem. Chem. Phys. 18(11), 7563-7572 (2016). https://doi.org/10.1039/C5CP05885F

51. S. Subudhi, D. Rath, K.M. Parida, A mechanistic approach towards the photocatalytic organic transformations over functionalised metal organic frameworks: a review. Catal. Sci. Technol. 8(3), 679-696 (2018). https://doi.org/10.1039/ C7CY02094E

52. A. Dhakshinamoorthy, Z. Li, H. Garcia, Catalysis and photocatalysis by metal organic frameworks. Chem. Soc. Rev. 47(22), 8134-8172 (2018). https://doi.org/10.1039/C8CS0 $0256 \mathrm{H}$

53. Z. Wu, X. Yuan, J. Zhang, H. Wang, L. Jiang, G. Zeng, Photocatalytic decontamination of wastewater containing organic dyes by metal-organic frameworks and their derivatives. ChemCatChem 9(1), 41-64 (2017). https://doi.org/10.1002/ cctc. 201600808

54. H.L. Jiang, B. Liu, Y.Q. Lan, K. Kuratani, T. Akita, H. Shioyama, F.Q. Zong, Q. Xu, From metal-organic framework to nanoporous carbon: toward a very high surface area and hydrogen uptake. J. Am. Chem. Soc. 133(31), 11854-11857 (2011). https://doi.org/10.1021/ja203184k

55. X. Ma, Y.X. Zhou, H. Liu, Y. Li, H.L. Jiang, A MOF-derived Co-CoO@N-doped porous carbon for efficient tandem catalysis: dehydrogenation of ammonia borane and hydrogenation of nitro compounds. Chem. Commun. 52(49), 7719-7722 (2016). https://doi.org/10.1039/C6CC03149H

56. B. Ma, P.Y. Guan, Q.Y. Li, M. Zhang, S.Q. Zang, MOFderived flower-like $\mathrm{MoS}_{2} @ \mathrm{TiO}_{2}$ nanohybrids with enhanced activity for hydrogen evolution. ACS Appl. Mater. Interfaces. 8(40), 26794-26800 (2016). https://doi.org/10.1021/acsam i. $6 \mathrm{~b} 08740$

57. X. Han, W.M. Chen, X. Han, Y.Z. Tan, D. Sun, Nitrogenrich $\mathrm{MOF}$ derived porous $\mathrm{Co}_{3} \mathrm{O}_{4} / \mathrm{N}-\mathrm{C}$ composites with superior performance in lithium-ion batteries. J. Mater. Chem. A 4(34), 13040-13045 (2016). https://doi.org/10.1039/C6TA0 $5096 \mathrm{D}$

58. X. Zhao, H. Yang, P. Jing, W. Shi, G. Yang, P. Cheng, A metal-organic framework approach toward highly nitrogendoped graphitic carbon as a metal-free photocatalyst for hydrogen evolution. Small 13(9), 1603279 (2017). https:// doi.org/10.1002/smll.201603279

59. L. Zhang, H.B. Wu, X.W. Lou, Metal-organic-frameworksderived general formation of hollow structures with high complexity. J. Am. Chem. Soc. 135(29), 10664-10672 (2013). https://doi.org/10.1021/ja401727n

60. W. Xia, A. Mahmood, R. Zou, Q. Xu, Metal-organic frameworks and their derived nanostructures for electrochemical energy storage and conversion. Energy Environ. Sci. 8(7), 1837-1866 (2015). https://doi.org/10.1039/C5EE00762C

61. Y. Du, R.Z. Chen, J.F. Yao, H.T. Wang, Facile fabrication of porous $\mathrm{ZnO}$ by thermal treatment of zeolitic imidazolate framework- 8 and its photocatalytic activity. J. Alloys Compd. 551, 125-130 (2013). https://doi.org/10.1016/j.jallc om.2012.10.045

62. L. Pan, T. Muhammad, L. Ma, Z.F. Huang, S. Wang, L. Wang, J.J. Zou, X. Zhang, MOF-derived C-doped ZnO prepared via a two-step calcination for efficient photocatalysis. Appl. Catal. B Environ. 189, 181-191 (2016). https://doi. org/10.1016/j.apcatb.2016.02.066

63. X. Han, X. He, F. Wang, J. Chen, J. Xu, X. Wang, X. Han, Engineering an $\mathrm{N}$-doped $\mathrm{Cu}_{2} \mathrm{O} @ \mathrm{~N}-\mathrm{C}$ interface with longlived photo-generated carriers for efficient photoredox catalysts. J. Mater. Chem. A 5(21), 10220-10226 (2017). https:// doi.org/10.1039/C7TA01909B

64. J. Chen, J. Yu, J. Zhang, Enhanced photocatalytic $\mathrm{CO}_{2}$ reduction activity of MOF-derived $\mathrm{ZnO} / \mathrm{NiO}$ porous hollow spheres. J. $\mathrm{CO}_{2}$ Util. 24, 548-554 (2018). https://doi. org/10.1016/j.jcou.2018.02.013

65. M. Lan, R.M. Guo, Y. Dou, J. Zhou, A. Zhou, J.R. Li, Fabrication of porous Pt-doping heterojunctions by using bimetallic MOF template for photocatalytic hydrogen generation. Nano Energy 33, 238-246 (2017). https://doi.org/10.1016/j. nanoen.2017.01.046

66. K.E. deKrafft, C. Wang, W. Lin, Metal-organic framework templated synthesis of $\mathrm{Fe}_{2} \mathrm{O}_{3} / \mathrm{TiO}_{2}$ nanocomposite for hydrogen production. Adv. Mater. 24(15), 2014-2018 (2012). https ://doi.org/10.1002/adma.201200330

67. L. He, L. Li, T. Wang, H. Gao, G. Li, X. Wu, Z. Su, C. Wang, Fabrication of $\mathrm{Au} / \mathrm{ZnO}$ nanoparticles derived from ZIF-8 with visible light photocatalytic hydrogen production and degradation dye activities. Dalton Trans. 43(45), 1698116985 (2014). https://doi.org/10.1039/C4DT02557A

68. Y. Zhang, J. Huang, Y. Ding, Porous $\mathrm{Co}_{3} \mathrm{O}_{4} / \mathrm{CuO}$ hollow polyhedral nanocages derived from metal-organic frameworks with heterojunctions as efficient photocatalytic water oxidation catalysts. Appl. Catal. B Environ. 198, 447-456 (2016). https://doi.org/10.1016/j.apcatb.2016.05.078

69. Y. Su, D. Ao, H. Liu, Y. Wang, MOF-derived yolk-shell CdS microcubes with enhanced visible-light photocatalytic activity and stability for hydrogen evolution. J. Mater. Chem. A 5(18), 8680-8689 (2017). https://doi.org/10.1039/C7TA00855D

70. D.P. Kumar, H. Park, E.H. Kim, S. Hong, M. Gopannagari, D.A. Reddy, T.K. Kim, Noble metal-free metal-organic framework-derived onion slice-type hollow cobalt sulfide nanostructures: enhanced activity of CdS for improving 
photocatalytic hydrogen production. Appl. Catal. B: Environ. 224, 230-238 (2018). https://doi.org/10.1016/j.apcat b.2017.10.051

71. Z.F. Huang, J. Song, K. Li, M. Tahir, Y.T. Wang, L. Pan, L. Wang, X. Zhang, J.J. Zou, Hollow cobalt-based bimetallic sulfide polyhedra for efficient all-pH-value electrochemical and photocatalytic hydrogen evolution. J. Am. Chem. Soc. 138(4), 1359-1365 (2016). https://doi.org/10.1021/ jacs.5b11986

72. X. Zhao, J. Feng, J. Liu, W. Shi, G. Yang, G.C. Wang, P. Cheng, An efficient, visible-light-driven, hydrogen evolution catalyst $\mathrm{NiS} / \mathrm{Zn}_{\mathrm{x}} \mathrm{Cd}_{1-\mathrm{x}} \mathrm{S}$ nanocrystal derived from a metal-organic framework. Angew. Chem. Int. Ed. 57(31), 9790-9794 (2018). https://doi.org/10.1002/anie.201805425

73. W. Chen, J. Fang, Y. Zhang, G. Chen, S. Zhao et al., CdS nanosphere-decorated hollow polyhedral ZCO derived from a metal-organic framework (MOF) for effective photocatalytic water evolution. Nanoscale 10(9), 4463-4474 (2018). https:// doi.org/10.1039/C7NR08943K

74. S. Wang, B.Y. Guan, Y. Lu, X.W.D. Lou, Formation of hierarchical $\mathrm{In}_{2} \mathrm{~S}_{3}-\mathrm{CdIn} \mathrm{S}_{4}$ heterostructured nanotubes for efficient and stable visible light $\mathrm{CO}_{2}$ reduction. J. Am. Chem. Soc. 139(48), 17305-17308 (2017). https://doi.org/10.1021/ jacs.7b10733

75. K. Meyer, M. Ranocchiari, J.A. van Bokhoven, Metal organic frameworks for photo-catalytic water splitting. Energy Environ. Sci. 8(7), 1923-1937 (2015). https://doi.org/10.1039/ C5EE00161G

76. W. Wang, X. Xu, W. Zhou, Z. Shao, Recent progress in metal-organic frameworks for applications in electrocatalytic and photocatalytic water splitting. Adv. Sci. 4(4), 1600371 (2017). https://doi.org/10.1002/advs.201600371

77. Y.J. Yuan, D. Chen, Z.T. Yu, Z.G. Zou, Cadmium sulfidebased nanomaterials for photocatalytic hydrogen production. J. Mater. Chem. A 6(25), 11606-11630 (2018). https://doi. org/10.1039/C8TA00671G

78. X. Chen, S.S. Mao, Titanium dioxide nanomaterials: synthesis, properties, modifications, and applications. Chem. Rev. 107(7), 2891-2959 (2007). https://doi.org/10.1021/cr050 0535

79. B. O’Regan, M. Grätzel, A low-cost, high-efficiency solar cell based on dye-sensitized colloidal $\mathrm{TiO}_{2}$ films. Nature 353, 737-740 (1991). https://doi.org/10.1038/353737a0

80. S. Bala, I. Mondal, A. Goswami, U. Pal, R. Mondal, Synthesis, crystal structure and optical properties of a naphthylbisimide-Ni complex: a framework on $\mathrm{TiO}_{2}$ for visible light $\mathrm{H}_{2}$ production. Dalton Trans. 43(42), 15704-15707 (2014). https ://doi.org/10.1039/C4DT02006E

81. R. Li, S. Wu, X. Wan, H. Xu, Y. Xiong, Cu/TiO 2 octahedralshell photocatalysts derived from metal-organic framework@ semiconductor hybrid structures. Inorg. Chem. Front. 3(1), 104-110 (2016). https://doi.org/10.1039/C5QI00205B

82. P. Minh-Hao, D. Cao-Thang, V. Gia-Thanh, T. Ngoc-Don, D. Trong-On, Visible light induced hydrogen generation using a hollow photocatalyst with two cocatalysts separated on two surface sides. Phys. Chem. Chem. Phys. 16(13), 5937-5941 (2014). https://doi.org/10.1039/c3cp54629b

83. B. Yan, L. Zhang, Z. Tang, M. Al-Mamun, H. Zhao, X. Su, Palladium-decorated hierarchical titania constructed from the metal-organic frameworks $\mathrm{NH}_{2}-\mathrm{MIL}-125$ (Ti) as a robust photocatalyst for hydrogen evolution. Appl. Catal. B Environ. 218, 743-750 (2017). https://doi.org/10.1016/j.apcat b.2017.07.020

84. S. Bala, I. Mondal, A. Goswami, U. Pal, R. Mondal, Co-MOF as a sacrificial template: manifesting a new $\mathrm{Co}_{3} \mathrm{O}_{4} / \mathrm{TiO}_{2}$ system with a $\mathrm{p}-\mathrm{n}$ heterojunction for photocatalytic hydrogen evolution. J. Mater. Chem. A 3(40), 20288-20296 (2015). https://doi.org/10.1039/C5TA05210F

85. J. Yao, J. Chen, K. Shen, Y. Li, Phase-controllable synthesis of MOF-templated maghemite-carbonaceous composites for efficient photocatalytic hydrogen production. J. Mater. Chem. A 6(8), 3571-3582 (2018). https://doi.org/10.1039/C7TA1 0284D

86. R. Li, L. Sun, W. Zhan, Y.A. Li, X. Wang, X. Han, Engineering an effective noble-metal-free photocatalyst for hydrogen evolution: hollow hexagonal porous micro-rods assembled from $\mathrm{In}_{2} \mathrm{O}_{3} @$ carbon core-shell nanoparticles. J. Mater. Chem. A 6(32), 15747-15754 (2018). https://doi. org/10.1039/C8TA04916E

87. J.Y. Xu, X.P. Zhai, L.F. Gao, P. Chen, M. Zhao, H.B. Yang, D.F. Cao, Q. Wang, H.L. Zhang, In situ preparation of a MOF-derived magnetic carbonaceous catalyst for visiblelight-driven hydrogen evolution. RSC Adv. 6(3), 2011-2018 (2016). https://doi.org/10.1039/C5RA23838B

88. J.D. Xiao, H.L. Jiang, Thermally stable metal-organic framework-templated synthesis of hierarchically porous metal sulfides: enhanced photocatalytic hydrogen production. Small 13(28), 1700632 (2017). https://doi.org/10.1002/smll.20170 0632

89. D.P. Kumar, J. Choi, S. Hong, D.A. Reddy, S. Lee, T.K. Kim, Rational synthesis of metal-organic framework-derived noble metal-free nickel phosphide nanoparticles as a highly efficient co-catalyst for photocatalytic hydrogen evolution. ACS Sustain. Chem. Eng. 4(12), 7158-7166 (2016). https://doi. org/10.1021/acssuschemeng.6b02032

90. X. Tang, J.H. Zhao, Y.H. Li, Z.J. Zhou, K. Li, F.T. Liu, Y.Q. Lan, Co-doped $\mathrm{Zn}_{1-\mathrm{x}} \mathrm{Cd}_{\mathrm{x}} \mathrm{S}$ nanocrystals from metal-organic framework precursors: porous microstructure and efficient photocatalytic hydrogen evolution. Dalton Trans. 46(32), 10553-10557 (2017). https://doi.org/10.1039/C7DT01970J

91. H. Chen, Z.G. Gu, S. Mirza, S.H. Zhang, J. Zhang, Hollow $\mathrm{Cu}-\mathrm{TiO}_{2} / \mathrm{C}$ nanospheres derived from a Ti precursor encapsulated MOF coating for efficient photocatalytic hydrogen evolution. J. Mater. Chem. A 6(16), 7175-7181 (2018). https ://doi.org/10.1039/C8TA01034J

92. M. Zhang, Y.L. Huang, J.W. Wang, T.B. Lu, A facile method for the synthesis of a porous cobalt oxide-carbon hybrid as a highly efficient water oxidation catalyst. J. Mater. Chem. A 4(5), 1819-1827 (2016). https://doi.org/10.1039/C5TA0 $7813 \mathrm{~J}$ 
93. Q. Lan, Z.M. Zhang, C. Qin, X.L. Wang, Y.G. Li, H.Q. Tan, E.B. Wang, Highly dispersed polyoxometalate-doped porous $\mathrm{Co}_{3} \mathrm{O}_{4}$ water oxidation photocatalysts derived from POM@ MOF crystalline materials. Chem. Eur. J. 22(43), 1551315520 (2016). https://doi.org/10.1002/chem.201602127

94. Y. Feng, J. Wei, Y. Ding, Efficient photochemical, thermal, and electrochemical water oxidation catalyzed by a porous iron-based oxide derived metal organic framework. J. Phys. Chem. C 120(1), 517-526 (2016). https://doi.org/10.1021/ acs.jpcc.5b11533

95. J. Wei, Y. Feng, Y. Liu, Y. Ding, $\mathrm{M}_{\mathrm{x}} \mathrm{Co}_{3-\mathrm{x}} \mathrm{O}_{4}(\mathrm{M}=\mathrm{Co}, \mathrm{Mn}$, $\mathrm{Fe}$ ) porous nanocages derived from metal-organic frameworks as efficient water oxidation catalysts. J. Mater. Chem. A 3(44), 22300-22310 (2015). https://doi.org/10.1039/ C5TA06411B

96. P. Liang, C. Zhang, H. Sun, S. Liu, M. Tade, S. Wang, Photocatalysis of C,N-doped $\mathrm{ZnO}$ derived from ZIF-8 for dye degradation and water oxidation. RSC Adv. 6(98), 95903-95909 (2016). https://doi.org/10.1039/C6RA20667K

97. B. Li, F. Li, S. Bai, Z. Wang, L. Sun, Q. Yang, C. Li, Oxygen evolution from water oxidation on molecular catalysts confined in the nanocages of mesoporous silicas. Energy Environ. Sci. 5(8), 8229-8233 (2012). https://doi.org/10.1039/ c2ee22059h

98. M. Yagi, M. Kaneko, Molecular catalysts for water oxidation. Chem. Rev. 101(1), 21-36 (2001). https://doi.org/10.1021/ cr9801081

99. F. Jiao, H. Frei, Nanostructured cobalt and manganese oxide clusters as efficient water oxidation catalysts. Energy Environ. Sci. 3(8), 1018-1027 (2010). https://doi.org/10.1039/c0020 $74 \mathrm{e}$

100. D. Hong, Y. Yamada, T. Nagatomi, Y. Takai, S. Fukuzumi, Catalysis of nickel ferrite for photocatalytic water oxidation using $\left[\mathrm{Ru}(\mathrm{bpy})_{3}\right]^{2+}$ and $\mathrm{S}_{2} \mathrm{O}_{8}{ }^{2-}$. J. Am. Chem. Soc. 134(48), 19572-19575 (2012). https://doi.org/10.1021/ja309771h

101. J. Huang, G. Hu, Y. Ding, M. Pang, B. Ma, Mn-doping and $\mathrm{NiFe}$ layered double hydroxide coating: effective approaches to enhancing the performance of $\alpha-\mathrm{Fe}_{2} \mathrm{O}_{3}$ in photoelectrochemical water oxidation. J. Catal. 340, 261-269 (2016). https://doi.org/10.1016/j.jcat.2016.05.007

102. D.M. Robinson, Y.B. Go, M. Mui, G. Gardner, Z. Zhang et al., Photochemical water oxidation by crystalline polymorphs of manganese oxides: structural requirements for catalysis. J. Am. Chem. Soc. 135(9), 3494-3501 (2013). https ://doi.org/10.1021/ja310286h

103. F. Lu, M. Zhou, Y. Zhou, X. Zeng, First-row transition metal based catalysts for the oxygen evolution reaction under alkaline conditions: basic principles and recent advances. Small 13(45), 1701931 (2017). https://doi.org/10.1002/smll.20170 1931

104. M. Zhou, Q. Weng, Z.I. Popov, Y. Yang, L.Y. Antipina, P.B. Sorokin, X. Wang, Y. Bando, D. Golberg, Construction of polarized carbon-nickel catalytic surfaces for potent, durable, and economic hydrogen evolution reactions. ACS Nano 12(5), 4148-4155 (2018). https://doi.org/10.1021/acsna no. $7 \mathrm{~b} 08724$
105. M. Zhou, Q. Weng, X. Zhang, X. Wang, Y. Xue, X. Zeng, Y. Bando, D. Golberg, In situ electrochemical formation of core-shell nickel-iron disulfide and oxyhydroxide heterostructured catalysts for a stable oxygen evolution reaction and the associated mechanisms. J. Mater. Chem. A 5(9), 4335-4342 (2017). https://doi.org/10.1039/C6TA09366C

106. X. Lu, C. Zhao, Electrodeposition of hierarchically structured three-dimensional nickel-iron electrodes for efficient oxygen evolution at high current densities. Nat. Commun. 6, 6616 (2015). https://doi.org/10.1038/ncomms7616

107. R. Li, W. Zhang, K. Zhou, Metal-organic-framework-based catalysts for photoreduction of $\mathrm{CO}_{2}$. Adv. Mater. 30(35), 1705512 (2018). https://doi.org/10.1002/adma.201705512

108. H. Zhang, T. Wang, J. Wang, H. Liu, T.D. Dao et al., Surfaceplasmon-enhanced photodriven $\mathrm{CO}_{2}$ reduction catalyzed by metal-organic-framework-derived iron nanoparticles encapsulated by ultrathin carbon layers. Adv. Mater. 28(19), 37033710 (2016). https://doi.org/10.1002/adma.201505187

109. C.Y. Hu, J. Zhou, C.Y. Sun, M.M. Chen, X.L. Wang, Z.M. $\mathrm{Su}$, HKUST-1 derived hollow $\mathrm{C}-\mathrm{Cu}_{2-\mathrm{x}} \mathrm{S}$ nanotube/g- $\mathrm{C}_{3} \mathrm{~N}_{4}$ composites for visible-light $\mathrm{CO}_{2}$ photoreduction with $\mathrm{H}_{2} \mathrm{O}$ vapor. Chemistry 24, 1-8 (2018). https://doi.org/10.1002/ chem.201804925

110. K. Khaletskaya, A. Pougin, R. Medishetty, C. Rosler, C. Wiktor, J. Strunk, R.A. Fischer, Fabrication of gold/titania photocatalyst for $\mathrm{CO}_{2}$ reduction based on pyrolytic conversion of the metal-organic framework $\mathrm{NH}_{2}$-MIL-125(Ti) loaded with gold nanoparticles. Chem. Mater. 27(21), 7248-7257 (2015). https://doi.org/10.1021/acs.chemmater.5b03017

111. S. Yan, Y. Yu, Y. Cao, Synthesis of porous $\mathrm{ZnMn}_{2} \mathrm{O}_{4}$ flowerlike microspheres by using MOF as precursors and its application on photoreduction of $\mathrm{CO}_{2}$ into $\mathrm{CO}$. Appl. Surf. Sci. 465, 383-388 (2019). https://doi.org/10.1016/j.apsus c. 2018.09 .211

112. J.M.R. Narayanam, C.R.J. Stephenson, Visible light photoredox catalysis: applications in organic synthesis. Chem. Soc. Rev. 40(1), 102-113 (2011). https://doi.org/10.1039/B9138 $80 \mathrm{~N}$

113. F. Wang, X. He, L. Sun, J. Chen, X. Wang, J. Xu, X. Han, Engineering an N-doped $\mathrm{TiO}_{2} @ \mathrm{~N}$-doped C butterfly-like nanostructure with long-lived photo-generated carriers for efficient photocatalytic selective amine oxidation. J. Mater. Chem. A 6(5), 2091-2099 (2018). https://doi.org/10.1039/ C7TA09166D

114. X. Han, X. He, L. Sun, X. Han, W. Zhan, J. Xu, X. Wang, J. Chen, Increasing effectiveness of photogenerated carriers by in situ anchoring of $\mathrm{Cu}_{2} \mathrm{O}$ nanoparticles on a nitrogendoped porous carbon yolk-shell cuboctahedral framework. ACS Catal. 8(4), 3348-3356 (2018). https://doi.org/10.1021/ acscatal.7b04219

115. A. Ahmed, M. Forster, J. Jin, P. Myers, H. Zhang, Tuning morphology of nanostructured ZIF-8 on silica microspheres and applications in liquid chromatography and dye degradation. ACS Appl. Mater. Interfaces. 7(32), 18054-18063 (2015). https://doi.org/10.1021/acsami.5b04979 
116. J. Li, X. Xu, X. Liu, W. Qin, M. Wang, L. Pan, Metalorganic frameworks derived cake-like anatase/rutile mixed phase $\mathrm{TiO}_{2}$ for highly efficient photocatalysis. J. Alloys Compd. 690, 640-646 (2017). https://doi.org/10.1016/j.jallc om.2016.08.176

117. Z. Guo, J.K. Cheng, Z. Hu, M. Zhang, Q. Xu, Z. Kang, D. Zhao, Metal-organic frameworks (MOFs) as precursors towards $\mathrm{TiO}_{\mathrm{x}} / \mathrm{C}$ composites for photodegradation of organic dye. RSC Adv. 4(65), 34221-34225 (2014). https://doi. org/10.1039/C4RA05429F

118. Q. Xu, Z. Guo, M. Zhang, Z. Hu, Y. Qian, D. Zhao, Highly efficient photocatalysts by pyrolyzing a $\mathrm{Zn}-\mathrm{Ti}$ heterometallic metal-organic framework. CrystEngComm 18(22), 40464052 (2016). https://doi.org/10.1039/C5CE01439E

119. H. Chen, K. Shen, J. Chen, X. Chen, Y. Li, Hollow-ZIF-templated formation of a $\mathrm{ZnO} @ \mathrm{C}-\mathrm{N}-\mathrm{Co}$ core-shell nanostructure for highly efficient pollutant photodegradation. J. Mater. Chem. A 5(20), 9937-9945 (2017). https://doi.org/10.1039/ C7TA02184D

120. Y. Feng, H. Lu, X. Gu, J. Qiu, M. Jia, C. Huang, J. Yao, ZIF-8 derived porous $\mathrm{N}$-doped $\mathrm{ZnO}$ with enhanced visible lightdriven photocatalytic activity. J. Phys. Chem. Solids 102, 110-114 (2017). https://doi.org/10.1016/j.jpcs.2016.11.022

121. X. Cao, B. Zheng, X. Rui, W. Shi, Q. Yan, H. Zhang, Metal oxide-coated three-dimensional graphene prepared by the use of metal-organic frameworks as precursors. Angew. Chem. Int. Ed. 126(5), 1428-1433 (2014). https://doi.org/10.1002/ ange. 201308013

122. G. Zhu, X. Li, H. Wang, L. Zhang, Microwave assisted synthesis of reduced graphene oxide incorporated MOFderived $\mathrm{ZnO}$ composites for photocatalytic application. Catal. Commun. 88, 5-8 (2017). https://doi.org/10.1016/j. catcom.2016.09.024

123. N. Salehifar, Z. Zarghami, M. Ramezani, A facile, novel and low-temperature synthesis of $\mathrm{MgO}$ nanorods via thermal decomposition using new starting reagent and its photocatalytic activity evaluation. Mater. Lett. 167, 226-229 (2016). https://doi.org/10.1016/j.matlet.2016.01.015

124. Q.X. Zeng, G.C. Xu, L. Zhang, H. Lin, Y. Lv, D.Z. Jia, Porous $\mathrm{CuO}$ nanofibers derived from a $\mathrm{Cu}$-based coordination polymer as a photocatalyst for the degradation of rhodamine B. New J. Chem. 42(9), 7016-7024 (2018). https://doi. org/10.1039/C8NJ00608C

125. H.M. Aly, M.E. Moustafa, M.Y. Nassar, E.A. Abdelrahman, Synthesis and characterization of novel $\mathrm{Cu}(\mathrm{II}) \mathrm{com}-$ plexes with 3-substituted-4-amino-5-mercapto-1,2,4-triazole Schiff bases: a new route to $\mathrm{CuO}$ nanoparticles. J. Mol. Struct. 1086, 223-231 (2015). https://doi.org/10.1016/j.molst ruc.2015.01.017

126. P. Mahata, T. Aarthi, G. Madras, S. Natarajan, Photocatalytic degradation of dyes and organics with nanosized $\mathrm{GdCoO}_{3}$. J. Phys. Chem. C 111(4), 1665-1674 (2007). https://doi. org/10.1021/jp066302q

127. J. Xu, J. Gao, Y. Liu, Q. Li, L. Wang, Fabrication of $\mathrm{In}_{2} \mathrm{O}_{3} /$ $\mathrm{Co}_{3} \mathrm{O}_{4}$-palygorskite composites by the pyrolysis of In/ Co-MOFs for efficient degradation of methylene blue and tetracycline. Mater. Res. Bull. 91, 1-8 (2017). https://doi. org/10.1016/j.materresbull.2017.03.018

128. Y. Lin, H. Wan, F. Chen, X. Liu, R. Ma, T. Sasaki, Twodimensional porous cuprous oxide nanoplatelets derived from metal-organic frameworks (MOFs) for efficient photocatalytic dye degradation under visible light. Dalton Trans. 47(23), 7694-7700 (2018). https://doi.org/10.1039/C8DT0 $1117 \mathrm{~F}$

129. C. Zhang, F. Ye, S. Shen, Y. Xiong, L. Su, S. Zhao, From metal-organic frameworks to magnetic nanostructured porous carbon composites: towards highly efficient dye removal and degradation. RSC Adv. 5(11), 8228-8235 (2015). https://doi. org/10.1039/C4RA15942J

130. K.Y. Andrew Lin, F.K. Hsu, W.D. Lee, Magnetic cobalt-graphene nanocomposite derived from self-assembly of MOFs with graphene oxide as an activator for peroxymonosulfate. J. Mater. Chem. A 3(18), 9480-9490 (2015). https://doi. org/10.1039/C4TA06516F

131. Y.F. Zhang, L.G. Qiu, Y.P. Yuan, Y.J. Zhu, X. Jiang, J.D. Xiao, Magnetic $\mathrm{Fe}_{3} \mathrm{O}_{4} @ \mathrm{C} / \mathrm{Cu}$ and $\mathrm{Fe}_{3} \mathrm{O}_{4} @ \mathrm{CuO}$ core-shell composites constructed from MOF-based materials and their photocatalytic properties under visible light. Appl. Catal. B Environ. 144, 863-869 (2014). https://doi.org/10.1016/j.apcat b.2013.08.019

132. Z.X. Li, B.L. Yang, Y.F. Jiang, C.Y. Yu, L. Zhang, Metaldirected assembly of five 4-connected MOFs: one-pot syntheses of MOF-derived $\mathrm{M}_{\mathrm{x}} \mathrm{S}_{\mathrm{y}} @ \mathrm{C}$ composites for photocatalytic degradation and supercapacitors. Cryst. Growth Des. 18(2), 979-992 (2018). https://doi.org/10.1021/acs.cgd.7b01463

133. S.K. Batabyal, S.E. Lu, J.J. Vittal, Synthesis, characterization, and photocatalytic properties of $\operatorname{In}_{2} \mathrm{~S}_{3}, \mathrm{ZnIn}_{2} \mathrm{~S}_{4}$, and $\mathrm{CdIn}_{2} \mathrm{~S}_{4}$ nanocrystals. Cryst. Growth Des. 16(4), 2231-2238 (2016). https://doi.org/10.1021/acs.cgd.6b00050

134. X. Yang, J. Chen, J. Hu, S. Zhao, J. Zhao, X. Luo, Metal organic framework-derived $\mathrm{Zn}_{1-\mathrm{x}} \mathrm{Co}_{\mathrm{x}}-\mathrm{ZIF} @ \mathrm{Zn}_{1-\mathrm{x}} \mathrm{Co}_{\mathrm{x}} \mathrm{O}$ hybrid photocatalyst with enhanced photocatalytic activity through synergistic effect. Catal. Sci. Technol. 8(2), 573-579 (2018). https://doi.org/10.1039/C7CY01979C

135. Y. Gong, X. Zhao, H. Zhang, B. Yang, K. Xiao et al., MOFderived nitrogen doped carbon modified g- $\mathrm{C}_{3} \mathrm{~N}_{4}$ heterostructure composite with enhanced photocatalytic activity for bisphenol a degradation with peroxymonosulfate under visible light irradiation. Appl. Catal. B Environ. 233, 35-45 (2018). https://doi.org/10.1016/j.apcatb.2018.03.077

136. Y. Jing, J. Wang, B. Yu, J. Lun, Y. Cheng et al., A MOFderived ZIF-8@ $\mathrm{Zn}_{1-\mathrm{x}} \mathrm{Ni}_{\mathrm{x}} \mathrm{O}$ photocatalyst with enhanced photocatalytic activity. RSC Adv. 7(67), 42030-42035 (2017). https://doi.org/10.1039/C7RA08763B

137. C. Yang, J. Cheng, Y. Chen, Y. Hu, CdS nanoparticles immobilized on porous carbon polyhedrons derived from a metalorganic framework with enhanced visible light photocatalytic activity for antibiotic degradation. Appl. Surf. Sci. 420, 252259 (2017). https://doi.org/10.1016/j.apsusc.2017.05.102

138. B. Hu, J.Y. Yuan, J.Y. Tian, M. Wang, X. Wang, L. He, Z. Zhang, Z.W. Wang, C.S. Liu, Co/Fe-bimetallic organic framework-derived carbon-incorporated cobalt-ferric mixed 
metal phosphide as a highly efficient photocatalyst under visible light. J. Colloid Interface Sci. 531, 148-159 (2018). https ://doi.org/10.1016/j.jcis.2018.07.037

139. S.J. Yang, J.H. Im, T. Kim, K. Lee, C.R. Park, MOF-derived $\mathrm{ZnO}$ and $\mathrm{ZnO} @ \mathrm{C}$ composites with high photocatalytic activity and adsorption capacity. J. Hazard. Mater. 186(1), 376-382 (2011). https://doi.org/10.1016/j.jhazm at.2010.11.019 